\title{
Canadian Airway Focus Group updated consensus-based recommendations for management of the difficult airway: part 2 . Planning and implementing safe management of the patient with an anticipated difficult airway \\ Mise à jour des Lignes directrices consensuelles pour la prise en charge des voies aériennes difficiles du Canadian Airway Focus Group : $2^{\text {ème }}$ partie. Planification et mise en ouvre d'une prise en charge sécuritaire du patient présentant des voies respiratoires difficiles anticipées
}

\author{
J. Adam Law, MD (1) - Laura V. Duggan, MD • Mathieu Asselin, MD • Paul Baker, MBChB, MD · \\ Edward Crosby, MD · Andrew Downey, MB · Orlando R. Hung, MD • George Kovacs, MD, MHPE • \\ François Lemay, MD $\cdot$ Rudiger Noppens, MD, PhD $\cdot$ Matteo Parotto, MD, PhD $\cdot$ Roanne Preston, MD • \\ Nick Sowers, MD · Kathryn Sparrow, MD - Timothy P. Turkstra, MD, MEng • David T. Wong, MD • \\ Philip M. Jones, MD, MSc • for the Canadian Airway Focus Group
}

Received: 19 October 2020/Revised: 11 March 2021/Accepted: 14 March 2021/Published online: 8 June 2021

(C) The Author(s) 2021

\begin{abstract}
Purpose Since the last Canadian Airway Focus Group (CAFG) guidelines were published in 2013, the published airway management literature has expanded substantially. The CAFG therefore re-convened to examine this literature and update practice recommendations. This second of two
\end{abstract}

The members of the Canadian Airway Focus Group are listed in Appendix.

J. A. Law, MD ( $\varangle)$

Department of Anesthesia, Pain Management and Perioperative Medicine, QEII Health Sciences Centre, Dalhousie University, Halifax Infirmary Site, 1796 Summer Street, Room 5452,

Halifax, NS B3H 3A7, Canada

e-mail: jlaw@dal.ca

L. V. Duggan, MD

Department of Anesthesiology and Pain Medicine, The Ottawa Hospital Civic Campus, University of Ottawa, Room B307, 1053 Carling Avenue, Mail Stop 249, Ottawa, ON K1Y 4E9, Canada

M. Asselin, MD

Département d'anesthésiologie et de soins intensifs, Université Laval, 2325 rue de l'Université, Québec, QC G1V 0A6, Canada articles addresses airway evaluation, decision-making, and safe implementation of an airway management strategy when difficulty is anticipated.

Source Canadian Airway Focus Group members, including anesthesia, emergency medicine, and critical care physicians were assigned topics to search. Searches were run in the Medline, EMBASE, Cochrane Central Register of Controlled Trials, and CINAHL

Département d'anesthésie du CHU de Québec, Hôpital EnfantJésus, 1401 18e rue, Québec, QC G1J 1Z4, Canada

P. Baker, MBChB, MD

Department of Anaesthesiology, Faculty of Medical and Health Science, University of Auckland, Private Bag 92019, Auckland 1142 , New Zealand

E. Crosby, MD

Department of Anesthesiology and Pain Medicine, The Ottawa Hospital, University of Ottawa, Suite CCW1401, 501 Smyth

Road, Ottawa, ON K1H 8L6, Canada

A. Downey, MB

Department of Anaesthesia, Perioperative and Pain Medicine,

Peter MacCallum Cancer Centre, Melbourne, Australia 
databases. Results were presented to the group and discussed during video conferences every two weeks from April 2018 to July 2020. These CAFG recommendations are based on the best available published evidence. Where high-quality evidence is lacking, statements are based on group consensus.

Findings and key recommendations Prior to airway management, a documented strategy should be formulated for every patient, based on airway evaluation. Bedside examination should seek predictors of difficulty with facemask ventilation $(F M V)$, tracheal intubation using videoor direct laryngoscopy (VL or DL), supraglottic airway use, as well as emergency front of neck airway access. Patient physiology and contextual issues should also be assessed. Predicted difficulty should prompt careful decision-making on how most safely to proceed with airway management. Awake tracheal intubation may provide an extra margin of safety when impossible VL or $D L$ is predicted, when difficulty is predicted with more than one mode of airway management (e.g., tracheal intubation and $F M V)$, or when predicted difficulty coincides with significant physiologic or contextual issues. If managing the patient after the induction of general anesthesia despite predicted difficulty, team briefing should include triggers for moving from one technique to the next, expert assistance should be sourced, and required equipment should be present. Unanticipated difficulty with airway management can always occur, so the airway manager

O. R. Hung, MD

Department of Anesthesia, Pain Management and Perioperative Medicine, QEII Health Sciences Centre, Dalhousie University, 1796 Summer Street, Halifax, NS B3H 3A7, Canada

G. Kovacs, MD, MHPE - N. Sowers, MD

Department of Emergency Medicine, QEII Health Sciences Centre, Dalhousie University, 1796 Summer Street, Halifax, NS B3H 3A7, Canada

F. Lemay, MD

Département d'anesthésiologie, CHU de Québec - Université Laval, Hôtel-Dieu de Québec. 11, Côte du Palais, Québec, QC G1R 2J6, Canada

R. Noppens, MD, PhD - T. P. Turkstra, MD, MEng

Department of Anesthesia \& Perioperative Medicine, Schulich School of Medicine \& Dentistry, University of Western Ontario, 339 Windermere Road, LHSC- University Hospital, London, ON N6A 5A5, Canada

M. Parotto, MD, PhD

Department of Anesthesiology and Pain Medicine, University of Toronto and Toronto General Hospital, Toronto, ON, Canada

Interdepartmental Division of Critical Care Medicine, University of Toronto, EN 442200 Elizabeth St, Toronto, ON M5G 2C4, Canada should have a strategy for difficulty occurring in every patient, and the institution must make difficult airway equipment readily available. Tracheal extubation of the atrisk patient must also be carefully planned, including assessment of the patient's tolerance for withdrawal of airway support and whether re-intubation might be difficult.

\section{Résumé}

Objectif Depuis la dernière publication des lignes directrices du Canadian Airway Focus Group (CAFG) en 2013, la littérature sur la prise en charge des voies aériennes s'est considérablement étoffée. Le CAFG s'est donc réuni à nouveau pour examiner la littérature et mettre à jour ses recommandations de pratique. Ce deuxième article traite de l'évaluation des voies aériennes, de la prise de décision et de la mise en cuvre sécuritaire d'une stratégie de prise en charge des voies aériennes lorsque des difficultés sont anticipées.

Sources Des sujets de recherche ont été assignés aux membres du Canadian Airway Focus Group, qui compte des médecins anesthésistes, urgentologues et intensivistes. Les recherches ont été réalisées dans les bases de données Medline, EMBASE, Cochrane Central Register of Controlled Trials et CINAHL. Les résultats ont été présentés au groupe et discutés lors de vidéoconférences toutes les deux semaines entre avril 2018 et juillet 2020. Les recommandations du CAFG sont fondées sur les

\footnotetext{
R. Preston, MD

Department of Anesthesia, BC Women's Hospital, 4500 Oak

Street, Vancouver, BC V6H 3N1, Canada

K. Sparrow, MD

Discipline of Anesthesia, St. Clare's Mercy Hospital, Memorial University of Newfoundland, 300 Prince Phillip Drive, St. John's, NF A1B V6, Canada

D. T. Wong, MD

Department of Anesthesia, Toronto Western Hospital, University Health Network, University of Toronto, 399 Bathurst St.,

Toronto, ON M5T2S8, Canada

P. M. Jones, MD, MSc

Department of Anesthesia \& Perioperative Medicine, Department of Epidemiology \& Biostatistics, Schulich School of Medicine \& Dentistry, University of Western Ontario, 339 Windermere Rd., LHSC- University Hospital, London, ON N6A 5A5, Canada
} 
meilleures données probantes publiées. Si les données probantes de haute qualité manquaient, les énoncés se fondent alors sur le consensus du groupe.

Constatations et recommandations clés Avant d'amorcer la prise en charge des voies aériennes, une stratégie documentée devrait être formulée pour chaque patient, en fonction de l'évaluation de ses voies aériennes. L'examen au chevet devrait rechercher les prédicteurs de difficultés pour la ventilation au masque, l'intubation trachéale utilisant la vidéolaryngoscopie ou la laryngoscopie directe, l'utilisation d'un dispositif supraglottique, ainsi que pour la cricothyroidotomie d'urgence. La physiologie $d u$ patient et ses problématiques contextuelles devraient également être évaluées. Les difficultés anticipées devraient inciter à prendre des décisions éclairées sur la façon la plus sécuritaire de procéder à la prise en charge des voies aériennes. L'intubation trachéale éveillée peut procurer une marge de sécurité supplémentaire lorsqu'on s'attend à ce que la vidéolaryngoscopie ou la laryngoscopie directe soient impossibles, lorsqu'on prévoit des difficultés pour plus d'un mode de prise en charge des voies aériennes ( $p$. ex., intubation trachéale et ventilation au masque), ou lorsque la difficulté prévue coïncide avec des problèmes physiologiques ou contextuels importants. En cas de choix de prise en charge des voies respiratoires du patient après induction de l'anesthésie générale malgré les difficultés prévues, les directives à l'équipe devraient inclure les déclencheurs pour passer d'une technique à l'autre, l'aide d'experts disponibles et l'équipement requis disponible. Des difficultés imprévues lors de la prise en charge des voies aériennes peuvent toujours survenir, de sorte que la personne responsable de la prise en charge des voies aériennes devrait avoir une stratégie pour chaque patient, et l'établissement doit rendre facilement disponible le matériel pour la prise en charge des voies aériennes difficiles. L'extubation trachéale du patient à risque doit également être soigneusement planifiée, y compris l'évaluation de la tolérance du patient lors du retrait du dispositif de soutien des voies aériennes et d'une réintubation potentiellement difficile.

Keywords guidelines · airway management - anticipated · difficult $\cdot$ intubation $\cdot$ tracheal

\section{Disclaimer}

These recommendations seek to reflect the latest published evidence regarding airway management. Where highquality evidence was lacking, expert opinion and consensus is presented. The recommendations do not represent standards of care and instead are suggestions for optimal practice. They should be applied with specific consideration of the individual patient's characteristics, the clinical context, the airway manager's skills, available resources, and local healthcare policies.

\section{Introduction}

Significant morbidity related to airway management continues to be reported, with the failure to plan for difficulty a recurrent theme. ${ }^{1-3}$ Most published airway guidelines focus on management of the alreadyunconscious patient when difficulty with tracheal intubation is encountered. Although less frequently addressed, avoiding having to manage an unexpectedly difficult airway almost certainly has greater potential to prevent patient harm. Airway-related morbidity can be prevented by careful patient evaluation and formulation of an airway management strategy (a co-ordinated series of plans) before proceeding with airway management. Lack of an airway evaluation or the failure to change usual practice based on its findings has been associated with morbidity. ${ }^{1}$ Airway evaluation includes examination for anatomic predictors of difficulty with tracheal intubation, facemask ventilation (FMV), supraglottic airway (SGA) use, and emergency front of neck airway access (eFONA). It should also include assessment of physiologic issues (e.g., apnea tolerance, aspiration risk, and altered hemodynamics) and the clinical context (e.g., case urgency, airway manager experience, equipment availability, and access to expert assistance). Airway evaluation should occur before starting airway management as well as before its discontinuation.

Video laryngoscopy (VL) has helped achieve more consistent glottic visualization and has improved firstattempt intubation success rates in the unconscious patient, especially in populations deemed to be at risk for difficult direct laryngoscopy (DL). ${ }^{4}$ Nevertheless, there remain patients who, based on thorough airway evaluation, would likely be more safely managed with awake tracheal intubation. This article addresses airway evaluation and provides recommendations to help formulate and implement a safe airway management strategy when difficulty is anticipated. In part 1 of these updated twopart recommendations, ${ }^{5}$ we address management of airway difficulties encountered in the unconscious patient, whether anticipated or not. Recommendations in both articles are meant to be broadly applicable to all specialties that have airway management in their practice mandate. 


\section{Methods}

The methods presented here are identical to those described in the companion part 1 article $^{5}$ and are reproduced here for the benefit of the reader. The Canadian Airway Focus Group (CAFG) is comprised of 17 members (see Appendix), with representation from across Canada as well as one member from each of New Zealand and Australia. The CAFG membership includes anesthesiologists, emergency physicians, and critical care physicians. Topics for review were divided among the members, with most assigned to two members. Members reviewed the literature published from 2011 onwards.

A medical librarian helped design and conduct the literature searches. Though not constituting a formal systematic review, databases searched included Medline, EMBASE, Cochrane Central Register of Controlled Trials, and CINAHL. Non-English and non-French, animal, manikin, and cadaver studies were excluded from searches, as were case reports, editorials, and letters. Nevertheless, team members had the discretion to include such material where relevant.

The CAFG met every two weeks by video conference from April 2018 to July 2020 to review findings and arrive at consensus regarding recommendations. Consistent with other recent airway management guidelines, ${ }^{6-9}$ we did not assign levels of evidence or strength of recommendation. This follows from a lack of what is considered high-level evidence seen in other medical fields. Randomized controlled trials of airway devices typically address efficacy (often in a population of low-risk elective surgical patients) but when critical events are uncommon (as with airway management), they are unable to evaluate the safety of techniques or decision-making. ${ }^{10}$ Information gleaned from large database studies is better able to capture uncommon events, ${ }^{10}$ but analysis is limited to association rather than causation and the population studied may not represent all practice environments. Thus, although evidence-based to the extent possible, some of the recommendations are based largely on expert consensus.

After review by the CAFG, draft documents were sent to several airway experts internationally (see Acknowledgments) for informal review and comment.

\section{Definitions}

The following definitions are used throughout the manuscript.

- Anticipated difficult airway. A difficult airway is predicted when the airway manager anticipates difficulty with any or all of FMV, tracheal intubation, SGA use, or eFONA.

- Awake tracheal intubation. Awake tracheal intubation (ATI) refers to tracheal intubation of a patient who is sufficiently conscious to maintain a patent airway unassisted, to maintain adequate gas exchange by spontaneous ventilation, and to protect the airway against the aspiration of gastric contents or other foreign material. Awake tracheal intubation can occur via the nasal, oral, or front of neck routes, and is facilitated by topical, regional, or local infiltrative airway anesthesia.

- At-risk tracheal extubation. The at-risk tracheal extubation is defined by the patient anticipated to be intolerant of tracheal extubation or who might be potentially difficult to re-intubate. Difficult reintubation might be anticipated based on pre-existing or de novo conditions (e.g., neck fusion or immobilization; upper airway edema).

\section{Prediction of difficulty with airway management}

Predicting difficulty underlies the planning for safe airway management. Expert opinion appearing in audits of airwayrelated morbidity and closed legal claim studies suggest that the "failure to prepare for failure" by omitting, not documenting, or not acting on positive findings of an airway evaluation figures prominently in cases with poor outcomes. ${ }^{1-3}$ Canadian data, ${ }^{3}$ and that from the USA, ${ }^{2}$ reveal that most anesthesia airway-related closed claims involved patients presenting for elective surgery ( $78 \%$ and $63 \%$, respectively).

Comprehensive airway evaluation includes physical examination of the patient and review of relevant physiologic and contextual issues, pertinent diagnostic imaging studies, and any available records of previous airway management. A history of previous difficulty is more often correctly predictive of difficulty than the bedside examination. ${ }^{11-15}$

Alone or in combination, the various bedside screening tests of anatomic features have been criticized for their poor performance in correctly predicting when difficulty will indeed occur with airway management. ${ }^{11,13,16}$ Nevertheless, the presence of certain anatomic features (Tables 1, 2, 3, 4, 5, 6, 7) should alert the airway manager to carefully consider the safest approach to airway management and which devices to have available; little downside will accrue if airway management turns out to be non-problematic. Conversely, when bedside screening suggests that no difficulty is expected, while more often correctly predictive of the actual outcome, ${ }^{11,16,17}$ 
Table 1 Published predictors of difficult tracheal intubation using direct laryngoscopy

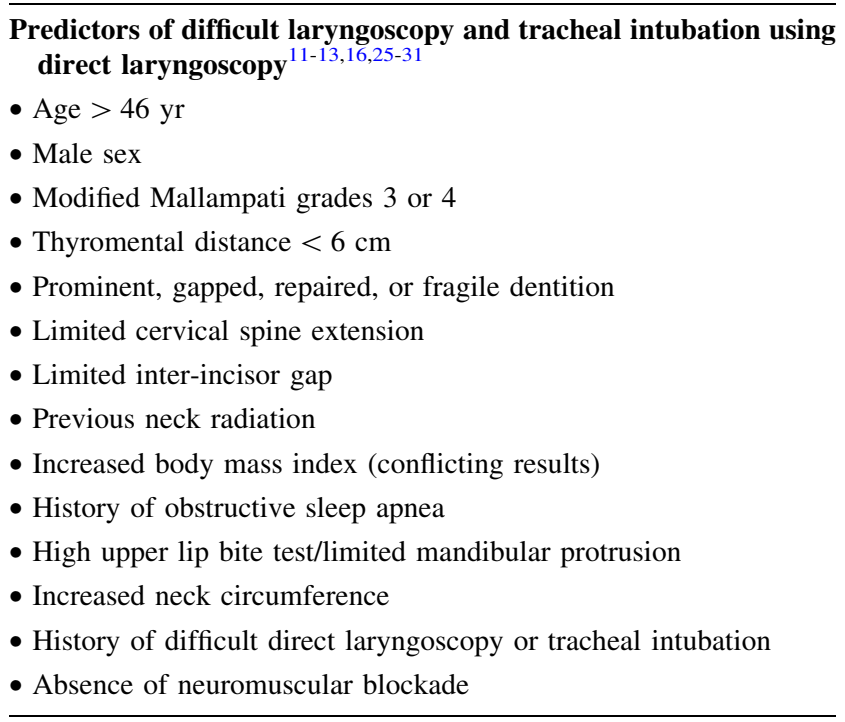

unanticipated difficulty can still occur, such that the airway manager must be ready with a strategy to address difficulty in all patients. Performing and documenting an airway evaluation is standard of care, and furthermore, acts as a cognitive prompt ${ }^{18}$ to consider the potential for difficulty with every patient. The CAFG recommends that all patients undergo airway evaluation before the initiation of airway management and before the discontinuation of airway support (e.g., tracheal extubation).

\subsection{Published predictors of difficult airway management}

Predictors of difficult tracheal intubation by DL and VL and other devices appear in Tables 1-3. Predictors of difficult FMV and difficult SGA use appear in Tables 4 and 5 , respectively. Predictors of difficult eFONA have not been prospectively studied but appear on a presumptive basis in Table 6 . The likelihood of actually encountering difficulty with any modality increases in proportion to the number of anatomic predictors of difficulty.

There are currently few published studies looking at predictors of difficulty with tracheal intubation using VL; this is a gap in the literature that should be addressed. Physiologic and contextual factors that may also impact planning and implementation of airway management appear in Table 7.

\subsection{The enhanced airway evaluation}

Patients with obstructing airway pathology may have distortions of upper or lower airway anatomy that cannot be identified by regular bedside screening tests. For the
Table 2 Published predictors of difficult tracheal intubation using video laryngoscopy

Predictors of difficulty with tracheal intubation using video laryngoscopy $^{32-36}$

- Abnormal neck anatomy (e.g., due to pathology, scar, remote radiation); thick neck

- Male sex

- Large tongue

- Thyromental distance $<6 \mathrm{~cm}$

- Short sternothyroid distance

- Limited cervical spine motion

- Limited mouth opening

- High upper lip bite test/limited mandibular protrusion

- Upper airway soiled by blood or vomitus

- Previously obtained high Cormack-Lehane grade during direct laryngoscopy

- Surgery type (head and neck or cardiac)

- Airway manager inexperience

Table 3 Published predictors of difficult tracheal intubation using other devices

Predictors of difficulty with tracheal intubation using other devices

Predictors of difficulty with optical stylet use $^{37}$

- Increased body mass index

- Decreased mouth opening

- Higher Cormack-Lehane grade

Predictors of difficult flexible bronchoscopic intubation under general anesthesia $^{38}$

- Visibility impaired by blood or secretions

- Higher neck skinfold thickness

- Larger tracheal tube inner diameter relative to scope outer diameter

patient with known or suspected obstructing glottic or supraglottic airway pathology, awake nasal endoscopy or oral VL performed under local anesthesia immediately before airway management can help clarify the extent and location of the problem. ${ }^{19}$ Subglottic pathology can be assessed by review of recent imaging studies. ${ }^{20}$ Point-ofcare ultrasound is playing an increasing role in physiologic diagnosis and evaluation of targeted management of resuscitation before, during, or after airway management. ${ }^{21}$

Another aspect to enhancing the airway exam in patients with significantly altered anatomy is to identify the location of the cricothyroid membrane (CTM). ${ }^{22}$ If visual inspection or palpation fails to identify the CTM location with certainty, it should be identified using ultrasonography and marked, ${ }^{22,23}$ with the patient's neck in an extended position. The patient can subsequently be positioned 
Table 4 Published predictors of difficulty with face-mask ventilation and difficult face-mask ventilation combined with difficult direct laryngoscopy

Predictors of difficult face-mask ventilation ${ }^{25,28,39-48}$

- Age $\geq 46$ yr

- Body mass index $\geq 35 \mathrm{~kg} \cdot \mathrm{m}^{-2}$

- Male sex

- History of snoring

- Obstructive sleep apnea

- Facial hair

- Previous neck radiation

- Thick and/or short neck

- Absence of teeth

- Modified Mallampati class 3 or 4

- Limited mandibular protrusion

- History of difficult tracheal intubation

- Absence of neuromuscular blockade

Predictors of difficult face-mask ventilation combined with difficult direct laryngoscopy (increasing odds ratio of difficulty if four or more risk factors are present $)^{44}$

- Age $\geq 46$ yr

- Body mass index $\geq 30 \mathrm{~kg} \cdot \mathrm{m}^{-2}$

- Male sex

- Obstructive sleep apnea

- Facial hair

- Modified Mallampati class 3 or 4

- Decreased thyromental distance (e.g., $<6 \mathrm{~cm}$ )

- Thick neck; neck mass or previous neck radiation

- Presence of teeth

- Limited cervical spine mobility

- Limited mandibular protrusion.

optimally for the intended airway technique; if eFONA is required, the patient can quickly be returned to the neckextended position to utilize the previously made marking. ${ }^{24}$

\section{Decision-making when difficult tracheal intubation is predicted}

Few published studies or guidelines specifically address which patients with predictors of difficult tracheal intubation can safely be managed after the induction of general anesthesia. Nevertheless, cues can be taken from the UK's NAP4 study ${ }^{1}$ and closed claims analyses. ${ }^{2,3}$ In NAP4, ATI was judged to have been underutilized in patients with known difficult airways. Eighteen cooperative patients with predictors of both difficult tracheal intubation and difficult FMV underwent intubation attempts after
Table 5 Published predictors of difficult supraglottic airway use in the adult patient

Predictors of difficult supraglottic airway insertion or ventilation (adult patient) ${ }^{49-52}$

- No teeth or poor dentition

- Reduced inter-incisor distance

- Mallampati 3 or 4

- Limited head/neck mobility

- Non-use of neuromuscular blockade

- Increased body mass index

- Neck circumference $>44 \mathrm{~cm}$

- Non-supine patient position

- Use of desflurane

- Use of smaller size supraglottic airway than recommended

- Multiple insertion attempts

Table 6 Presumptive predictors of difficulty with front of neck airway access

Presumptive predictors of difficulty with front of neck airway access

- Indistinct anatomic landmarks due to obesity, thick or short neck, subcutaneous emphysema, or surgical scarring

- Overlying hematoma, induration, inflammation, or tumour

- Previous neck radiation

- Female sex

- Laterally deviated larynx

- Limitation to head or neck extension-e.g., fixed flexion deformity

Table 7 Physiologic and contextual issues that may impact airway management

Physiologic issues that may impact airway management ${ }^{53,54}$

- Apnea intolerance, based on:

$\bigcirc$ Decreased functional residual capacity

$\bigcirc$ Increased oxygen consumption

$\bigcirc$ Baseline hypoxemia; decreased $\mathrm{PaO}_{2} / \mathrm{FiO}_{2}$ ratio

Acid-base disturbance with respiratory compensation.

- Full stomach or other major risk factor for aspiration.

- Hemodynamic instability.

Contextual issues that may impact airway management

- Adverse location (e.g., remote location, difficult access to patient, adverse lighting conditions)

- Help/backup unavailable (e.g., because of time of day or remote location)

- Airway manager inexperience with chosen or required technique

- Lack of equipment

- Team inexperienced with difficult airway management

- Poor team communication 
induction of general anesthesia. All suffered complications and two patients died. ${ }^{1}$

When difficulty is predicted, ATI enables patients to maintain their own airway patency, gas exchange, and protection of the lower airway against aspiration during tracheal intubation; thus, ATI potentially provides a safety benefit. Conversely, despite possessing predictors of difficult laryngoscopy or intubation, some patients might still be safely managed after induction of general anesthesia. When difficult laryngoscopy or intubation is predicted, deliberate consideration of the following four questions can help the airway manager decide whether ATI is indicated or if management might safely occur after induction (Fig. 1).

\section{A. Does the patient clearly need awake tracheal} intubation?

Significant and obvious anatomic deformities or pathologic alterations of the head and neck are often most safely managed with ATI. Examples include (but are not limited to) the patient with very limited mouth opening, a fixed flexion deformity of the head and neck, or a pathologically enlarged tongue. In such patients, there is often no chance that standard techniques such as DL, Macintosh blade video laryngoscopy (Mac-VL) or hyperangulated blade VL (HA-VL) are feasible. Alternatives to these standard techniques are likely to be less familiar to the airway manager or take longer to use, especially in the context of distorted anatomy. Thus, if managing the airway in apneic conditions after induction of general anesthesia, this could put the patient at risk of significant hypoxemia. In addition, anatomy altered to this extent will often also predict difficulty with fallback modes of ventilation such as FMV or SGA use (see next section). For these reasons, ATI is a safer option.

\section{B. Is difficulty also predicted with fallback} ventilation options?

When difficult tracheal intubation is predicted, no matter how effective the primary device chosen to facilitate

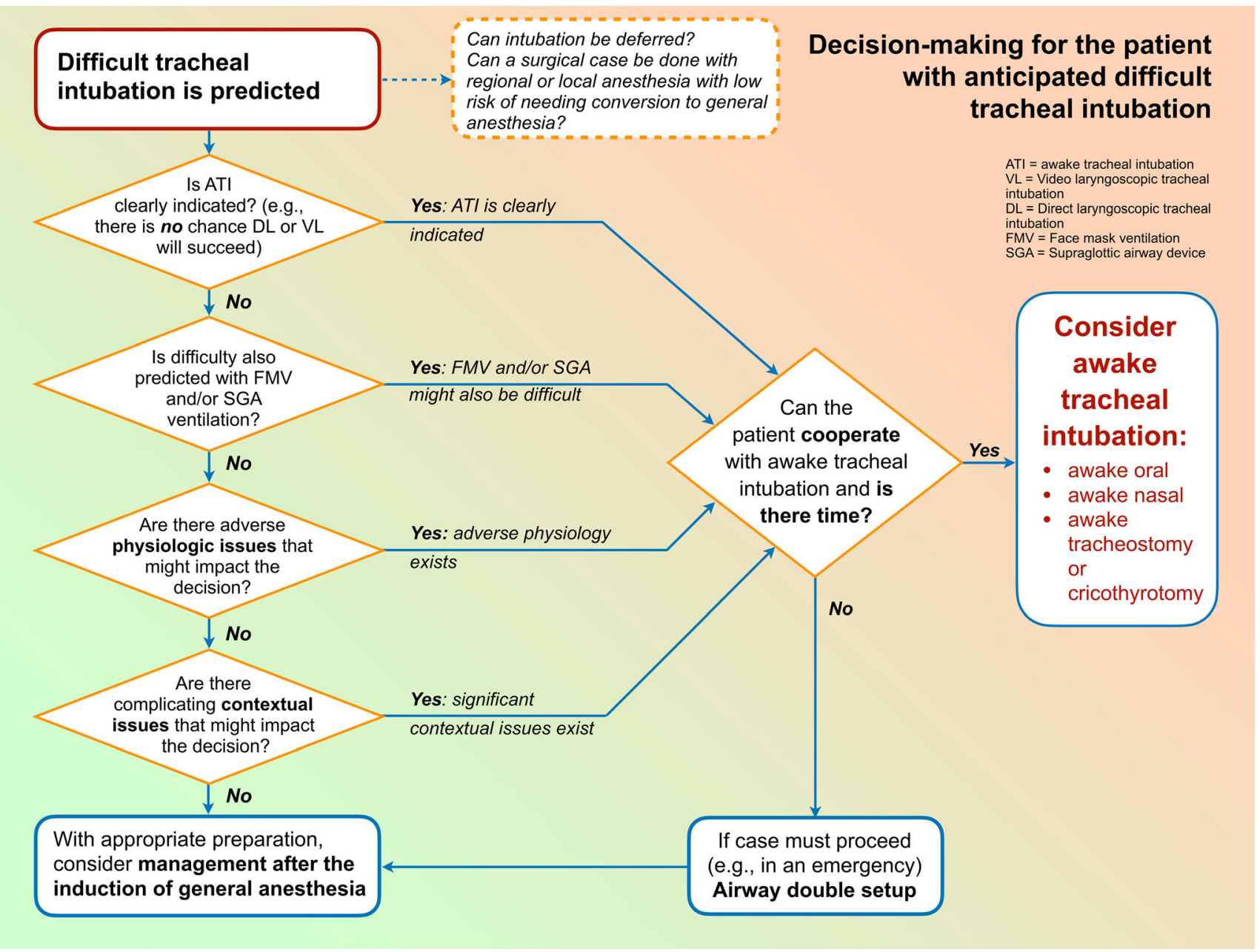

Fig. 1 Flow diagram: Decision-making when difficult tracheal intubation is predicted. ATI $=$ awake tracheal intubation; DL = direct laryngoscopy; FMV = face-mask ventilation; SGA = supraglottic airway; VL = video laryngoscopy. 
tracheal intubation may be, all have a failure rate. When this occurs, FMV or SGA ventilation will be needed between attempts. Unfortunately, when difficult or failed tracheal intubation has occurred, difficult FMV is more likely, ${ }^{55-57}$ and vice versa. ${ }^{46,57}$ Similarly, failed SGA ventilation is associated with a higher incidence of difficult FMV. ${ }^{49,52}$ This phenomenon has been referred to as the "composite failure of airway management". 55 Tracheal intubation and FMV are reported to have predictors of difficulty common to both modalities ${ }^{44}$ (Table 4). Thus, when difficulty is predicted with one mode (e.g., tracheal intubation), the airway manager must be especially vigilant in assessing the patient for predicted difficulty with other modes (e.g., FMV, SGA ventilation, or front of neck airway access [FONA]). When significant difficulty is predicted with two or more modes, (e.g., tracheal intubation and FMV), ATI should be strongly considered as a potentially safer option.

\section{Is there any physiologic compromise?}

Physiologic compromise (Table 7) complicates and distracts from difficult airway management. ${ }^{53,54}$ It is also accentuated by induction of anesthesia that additionally risks hypoxemia, aspiration, or hemodynamic instability in those at risk. Separation of difficult airway management from induction of anesthesia is therefore of value; thus, ATI is likely the optimal choice for both safety and controlling the cognitive load of the airway manager.

Rarely, physiologic issues might be the sole indication for ATI, without any anatomic predictors of difficulty with airway management, as with a critically ill patient with significant lung parenchymal disease and a high shunt fraction. $^{58}$

\section{Are there any complicating contextual issues?}

Contextual issues (Table 7) might also favour ATI when difficult tracheal intubation is predicted. For example, when an airway manager is practicing in a resource-austere setting without access to expert assistance or VL, the use of ATI for the predicted difficult airway patient might improve the margin of safety if patient transfer to a more fully equipped facility is not an option.

As indicated in Fig. 1, if all of the preceding questions are answered in the negative, airway management after induction of general anesthesia may be considered. Nevertheless, it must be emphasized that this decision remains one of clinical judgement and that the algorithm based on these questions has not been validated in a randomized-controlled trial. An airway manager's individual threshold for performing ATI or other patient or system factors might also impact the decision. Conversely, if the pathway through the Figure 1 flow diagram has suggested that ATI might be a safer option, a fifth question must then be addressed, as follows.
6.1 Can the patient cooperate with ATI and is there time?

Proceeding with ATI generally requires both a cooperative patient and time for its completion. If these are lacking, options become more limited. In some critically ill patients, physiologic disturbances or an alteration in sensorium can make compliance with ATI challenging. This may guide the airway manager towards tracheal intubation after the induction of general anesthesia if airway management must proceed at that time (Fig. 1). Under these circumstances, regardless of how the induction of general anesthesia proceeds (e.g., with or without an attempt to maintain spontaneous ventilation), "double set-up" (Table 8) preparations for eFONA are recommended in case of need. This decision must be balanced against the benefit of delaying tracheal intubation in favour of less invasive approaches for ventilation/oxygenation or further medical management, if this is an option.

When difficulty is predicted, tracheal intubation should only proceed after the induction of general anesthesia when the estimated margin of safety is equivalent to an awake technique. In the elective surgical setting, perceived time pressure or airway manager discomfort with performing ATI must not play a role in decision-making for the patient with a difficult airway. Rather, help might be sought from a colleague with more experience in performing ATI.

\section{Implementation of the planned strategy when difficult tracheal intubation is predicted}

When difficult tracheal intubation is predicted, the following principles are common to implementing the plan, whether by ATI or after induction of general anesthesia:

- An additional experienced airway manager should be sourced. For more challenging situations, having this individual standing by in the room is advisable;

- The airway manager should brief the assembled team on the intended strategy for securing the airway;

- The briefing should include the planned response to failure of the intended technique;

- An SGA must be available for use as a rescue technique in the event of failed tracheal intubation;

- During the briefing, the airway manager should include triggers for declaring failure of one technique and proceeding to the next. At this time, all members of the team should be explicitly empowered to state when they believe a trigger has occurred. 
Table 8 Components of the "double set-up" in airway management

The "double set-up" in airway management: components

- Mark the location of the cricothyroid membrane with the patient's head and neck extended. Use ultrasound guidance if skilled.

- Decide who will undertake eFONA. This should be someone other than the primary airway manager if possible.

- Ensure equipment for the chosen eFONA technique is present in the room, opened, and ready to use.

- Brief the team before induction, including the potential need for eFONA and triggers for proceeding with it.

Rationale for the double set-up in airway management

- The double set-up will help focus everyone's attention on the anticipated airway management difficulty and patient risk.

- Equipment and personnel are present in the room while the airway is being secured.

- eFONA will be perceived as part of the plan, rather than the rescue of a failed plan. Timelier onset of eFONA may result.

eFONA $=$ emergency front of neck airway access.

7.1 Awake tracheal intubation in the patient with anticipated difficult tracheal intubation

When performed by experienced airway managers, high success and low complication rates have been reported with ATI. ${ }^{59-61}$ All awake techniques are facilitated by one or more of topical, regional, or local infiltrative anesthesia, often aided by small doses of adjunctive systemic medications. Any discomfort with ATI is typically brief and patients are usually accepting of an airway manager's recommendation for airway management, especially when its safety aspects are discussed. ${ }^{62}$

The Difficult Airway Society in the UK has recently published comprehensive guidelines on ATI. ${ }^{63}$

\subsubsection{Topical airway anesthesia for awake tracheal intubation}

Topically applied lidocaine provides good conditions for ATI and has a favourable safety profile compared with other agents. Used for ATI, a maximum dosage of 9 $\mathrm{mg} \cdot \mathrm{kg}^{-1}$ (lean body weight) of topical lidocaine has been recommended by the DAS ATI guidelines, ${ }^{63}$ although there have been reports of symptoms and signs of toxicity at this and lower doses in volunteers. ${ }^{64}$ Thus, the lowest lidocaine dose compatible with adequate conditions for the procedure should be used. There is no published evidence to recommend one topicalization regime over another, nor is there evidence that percutaneous nerve blocks are superior to topical airway anesthesia.

\subsubsection{Adjunctive systemic medications during awake tracheal intubation}

Systemic medications should complement topical airway anesthesia and should not be used to compensate for its ineffective application. The goal of therapy should be considered in choosing a systemic agent and its dosage. Anxiolysis and sometimes, amnesia, may be achieved with a benzodiazepine or dexmedetomidine ${ }^{65,66}$; decreasing airway reflexes may be aided by opioids, such as a lowdose remifentanil infusion. Sedation is a secondary and arguably less desirable goal during ATI, as it may impair the patient's ability to cooperate with application of topical anesthesia. ${ }^{67}$ The use of systemic medication in the patient undergoing ATI because of obstructing pathology must be carefully considered, recognizing that total loss of airway patency has been reported. ${ }^{68}$

Reviews on the use of systemic medications during ATI have been published. ${ }^{65,69}$ No single systemic agent has yet been definitively identified as the best to aid ATI, although dexmedetomidine has been established as an effective sedative for the purpose. ${ }^{6,69}$ Airway managers' preferences and familiarity with the various drugs are important factors to help guide their choice of agent.

\subsubsection{Choice of device to facilitate awake tracheal intubation}

ATI has traditionally been accomplished using a flexible bronchoscope (FB). More recently, HA-VL has also been reported to successfully facilitate ATI via the oral ${ }^{70,71}$ and nasal $^{72}$ routes. While each class of device has benefits and limitations when used for ATI (Table 9), they appear to have comparable safety profiles. ${ }^{73,74}$ If one technique fails, the other may prove successful. Both options require effective topical airway anesthesia for ATI. Note that awake VL will not be an option for some difficult anatomical presentations (Table 9). Nevertheless, it is important for the airway manager to appreciate that for many difficult airway situations, ATI can proceed with a variety of devices. ${ }^{75}$

Other options to facilitate ATI include optical stylets, the concurrent use of VL and the FB, or awake placement of an SGA under topical anesthesia to provide a conduit for FB-aided intubation. ${ }^{77}$ The latter is particularly effective in the setting of redundant upper airway tissue, as seen with significant obesity, patients with obstructive sleep apnea, and some children with predicted difficult airways. ${ }^{78-80}$ Blind passage of a tracheal tube through an SGA without being facilitated by a FB is not recommended for ATI.

The CAFG recommends that all airway managers should be competent in ATI. This includes effective application of topical airway anesthesia as well as the use 
Table 9 Benefits of and limitations to the use of VL and FB for facilitating awake tracheal intubation

Use of hyper-angulated video laryngoscopy for awake tracheal intubation $^{73,74,76}$

- Enables a broad view of anatomy and good spatial awareness; facilitates a shared mental model with other team members.

- The tracheal tube can be directed to and observed to pass between the vocal cords.

- The "pink-out" that can occur if a FB abuts mucosa is avoided.

- Variously sized styleted tracheal tubes can be prepared; it is easier to substitute a smaller sized tracheal tube than re-load and re-insert a FB if the initial tube size is too large.

- Space is created in the oropharynx with gentle lifting of the blade during VL.

- As a familiar technique, VL may allow more rapid ATI than the FB.

- VL may not be an option with some anatomic and pathologic abnormalities (e.g., very limited mouth opening, fixed neck flexion deformity, enlarged tongue, or base of tongue masses).

Use of flexible bronchoscopy for awake tracheal intubation

- Passage of the FB and tracheal tube can occur by the nasal route, if necessary.

- Navigation is possible in all planes around obstructing masses (e.g., a base of tongue lesion).

- Advanced to just above the carina, the FB acts as a guide for tracheal tube advancement to, through, and beyond the larynx. The FB can also be used to confirm successful tracheal intubation and can be used to ensure correct tube positioning above the carina.

- The FB can be used for some situations where anatomic constraints preclude use of awake VL. Thus, airway managers must also attain and maintain skills with the FB for ATI.

- Using the FB routinely for ATI maintains skills in a critical technique.

- Permits examination of the trachea to rule out injury, or to ensure a tracheal tube is placed distal to a known or suspected penetrating tracheal injury or fistula.

ATI = awake tracheal intubation; FB = flexible bronchoscope; $\mathrm{VL}=$ video laryngoscopy.

of both the FB and VL for that purpose. Maintaining skills in ATI is important to ensure that airway manager discomfort is not a deterrent for performing an awake technique when clinically indicated.

\subsubsection{Failed awake intubation}

Awake tracheal intubation may fail ${ }^{59-61}$ for a number of reasons, including inadequate topical anesthesia, excess sedation, adverse anatomy, or a lack of patient cooperation. The airway manager must carefully consider the next steps. Simply proceeding with induction of general anesthesia after failed ATI has resulted in major morbidity and death. ${ }^{1,81}$ Options include deferral of an elective surgical case, summoning more experienced help, or application of additional topical anesthesia. Simply deepening systemic sedation may be hazardous. For an urgent or emergency situation that cannot be deferred, tracheal intubation after the induction of general anesthesia must sometimes be undertaken, with a "double set-up" preparation for eFONA (please see section 6.2 and Table 8).

Reports of complete airway obstruction occurring during attempted ATI have been published, ${ }^{59,68,82,83}$ most often in the setting of advanced obstructing airway pathology. Possible causes include excess sedation, or a direct adverse effect of local anesthetic on upper airway patency. ${ }^{84,85}$ The latter phenomenon does not imply that ATI should be avoided in patients with obstructing airway pathology, but rather, that the airway manager should be ready with an alternate plan, including rapidly proceeding with eFONA if a "cannot ventilate, cannot oxygenate" (CVCO) situation occurs. It should also be noted that if eFONA is anticipated to be difficult and prolonged (e.g., due to a thick neck, previous irradiation or overlying induration or infection), it should not be considered a viable fallback technique. In this situation, awake cricothyrotomy or tracheotomy under local infiltrative anesthesia (next section) may be the more prudent planned approach.

\subsubsection{Awake tracheotomy or awake cricothyrotomy}

Elective FONA by tracheotomy or cricothyrotomy is a good option as a planned primary technique when great difficulty is predicted with airway management-e.g., with a friable airway cancer and/or severely narrowed airway. Requiring patient cooperation, local infiltrative anesthesia, and most often performed by a surgeon, this option might be chosen in the following situations, among others:

- For the patient presenting with advanced obstructing upper airway pathology that might cause significant technical difficulties during attempted awake oral or nasal intubation (e.g., a very friable, large base of tongue tumour);

- When the glottic opening is very small (e.g., because of obstructing tumour burden) and FB-aided awake oral or nasal intubation would transiently completely occlude the patient's breathing during intubation, possibly causing panic and loss of patient cooperation;

- When both oral and nasal routes are not available (e.g., because of substantial disruption by trauma or distortion by advanced upper airway pathology);

- When a surgeon elects to do awake tracheotomy as an alternative to awake oral or nasal intubation if the 
airway manager is not confident that ATI is a feasible option.

\subsubsection{The "impossible airway" and awake institution of extracorporeal membrane oxygenation as a primary technique}

An impossible airway might be predicted in clinical situations where all four of FMV, SGA use, tracheal intubation, and FONA are anticipated to fail. Failed FONA might occur with obstructing pathology distal to the thoracic inlet (or planned FONA site), or when anterior neck pathology precludes access to the trachea by cricothyrotomy or tracheotomy. In these circumstances, establishing awake veno-venous or veno-arterial extracorporeal membrane oxygenation (ECMO) prior to or as a replacement for airway intervention might represent a safer option to maintain oxygenation. ${ }^{86}$ This underlying rationale, together with continually improving technology and expertise in ECMO, supports its use in the context of the impossible airway situation, although the currently supportive evidence appears chiefly as single case reports ${ }^{87-89}$ and case series, ${ }^{90}$ with the attendant potential for positive publication bias. The decision to initiate ECMO prior to airway intervention should ideally occur by multidisciplinary consultation involving surgeons, anesthesiologists, perfusionists, and critical care staff, considering both diagnostic findings and clinical signs and symptoms such as stridor, dyspnea, and orthopnea.

Even in experienced hands, establishing ECMO may be complicated and is time-consuming. Therefore, it has no role as a rescue technique for a failed airway encountered after the induction of general anesthesia. This is distinct from the use of veno-arterial ECMO in the cardiac arrest scenario, when extracorporeal cardiopulmonary resuscitation is possible when specific criteria are met. In this case, patients are often transitioned to mechanical circulatory support some time after cardiac arrest and, although in a low-flow state, they will have received continuous ventilation and oxygenation throughout.

\subsection{Management of the patient with anticipated difficult tracheal intubation after the induction of general anesthesia}

If difficulty with management is predicted but the airway manager has elected to proceed with tracheal intubation after the induction of general anesthesia, close attention must be paid to details of implementation. Guiding principles are as follows:

- Position the patient optimally for the planned technique;
- Pre-oxygenate;

- Use apneic oxygenation throughout;

- Fully prepare equipment for the planned primary intubation approach;

- Fully prepare equipment for alternate intubation techniques;

- Prepare an appropriately sized second-generation SGA for rescue ventilation and oxygenation;

- Brief the team on the planned progression of techniques, with objective triggers for transitioning to the next technique;

- Review and communicate the exit strategy ${ }^{5}$ to be used if tracheal intubation fails;

- Ensure that an additional experienced airway manager has been sourced.

Further details appear below.

\subsubsection{Patient positioning}

Appropriate patient positioning can help with technical aspects of airway management and by increasing safe apnea time.

\section{- Positioning for laryngoscopy and intubation.} Published literature suggests optimal patient positioning for direct- and Mac-VL is the "sniffing" position. ${ }^{91-94}$ This is typically obtained by aligning the patient's tragus with their sternum in the horizontal plane, by flexing the lower neck and extending the head. ${ }^{95}$ In the obese patient, similar alignment can be achieved in several ways, including commercial positioning devices, back-of-bed elevation, or by creating a ramp with folded sheets. ${ }^{96-104}$ There is currently insufficient evidence to recommend a specific patient position for the use of hyper-angulated videolaryngoscopes, which can be used in both the sniffing and neutral positions of the head and neck. The patient positioned in the neutral position with cervical spine immobilization is sub-optimally positioned for DL and Mac-VL, so that an experienced airway manager and alternate devices such as an HA-VL should be available. ${ }^{105}$

- Positioning for FMV. Although the evidence is sparse, the sniffing position appears to be beneficial for improving upper airway patency ${ }^{106}$ and facilitating FMV. ${ }^{107}$

- Positioning for SGA insertion. Product monographs for SGAs typically espouse a sniffing position for insertion, with head extension and lower neck flexion. ${ }^{108,109}$ Furthermore, a prospective study has indicated reduced neck mobility to be a risk factor for difficult SGA insertion. ${ }^{52}$ With respect to ventilation once placed, a systematic review and meta-analysis by 
Kim and colleagues compared the performance of a variety of SGAs in the flexed, neutral, and extended positions. ${ }^{110}$ Compared with the neutral position, the flexed position improved device seal but impaired ventilation as well as the view of the glottis obtainable with flexible endoscopy. Conversely, compared with the neutral position, the extended position worsened the device seal but had no effect on ventilation effectiveness or endoscopic view. These findings suggest that after insertion, SGAs should generally be used with the head and neck in the neutral position.

- Positioning for eFONA. Although published evidence is lacking, full extension of the head and neck is likely the optimal position for eFONA. ${ }^{4}$ This will be aided by placing a bolster or pillow under the patient's shoulders. There is some evidence that full neck extension may increase the height of the CTM by as much as $30 \% .^{111}$ Pre-induction landmarking of the CTM (e.g., by ultrasound or palpation) should also occur in a position of full neck extension, as the CTM location may change significantly when re-positioning from a neutral to an extended position. ${ }^{111}$

\subsubsection{Pre-oxygenation}

The American Society of Anesthesiologists and Canadian Medical Protective Association closed claims publications revealed that many patients who sustained airway-related morbidity were healthy and presenting for elective surgery. $^{2,3}$ In some cases, harm might have been prevented or mitigated by closer attention to the use of pre-oxygenation and apneic oxygenation techniques to prolong the safe apnea time. Safe apnea time relates to the volume of the patient's functional residual capacity (FRC), effective de-nitrogenation of the FRC, and oxygen consumption. Of these, FRC and de-nitrogenation are modifiable. As described by Mosier in a recent editorial, three scenarios might be considered, based on the risk of oxygen desaturation with the onset of apnea ${ }^{58}$ :

- Low to moderate risk of oxygen desaturation: Describing many elective surgical patients with a predicted ample FRC and low shunt fraction, the FRC should be de-nitrogenated by pre-oxygenation with $100 \%$ oxygen for three minutes of tidal volume breathing, eight vital capacity breaths over 60 sec, ${ }^{12,113}$ or until the measured fraction of exhaled oxygen $\left(\mathrm{FeO}_{2}\right)$ exceeds $0.9 .^{114}$ More than one strategy has been described for standard pre-oxygenation: 1) use of a tightly applied cuffed face mask attached to an anesthetic circuit or manual resuscitator with $\mathrm{O}_{2}$ flow $\geq$ $10 \mathrm{~L} \cdot \mathrm{min}^{-1}$, or 2) use of a nonrebreathing face mask with oxygen flow at "flush rate" (i.e., $\geq 40$
$\left.\mathrm{L} \cdot \mathrm{min}^{-1}\right){ }^{115}$ The high flow rate helps match the patient's peak inspiratory flow rate, thus avoiding dilution by room air during peak demand. There is evidence that safe apnea time can be further extended with efforts to increase FRC, e.g., by patient positioning in the semi-seated (Fowler's), reverse Trendelenburg, or seated upright position, ${ }^{116-120}$ if hemodynamics allow. This is particularly applicable to morbidly obese patients and term parturients. ${ }^{121-124}$ In addition, gentle FMV between loss of consciousness and beginning laryngoscopy is advocated.

- Moderate to high risk of oxygen desaturation: For the patient at higher risk of oxygen desaturation with the onset of apnea, such as those with lower FRC and increased shunt fraction, the optimal pre-oxygenation strategy likely involves use of positive end-expiratory pressure or non-invasive positive pressure ventilation (NIV) during pre-oxygenation, ${ }^{125-128}$ together with back up or reverse Trendelenburg positioning. The concurrent use of standard nasal cannulae with NIV can augment pre-oxygenation and subsequently provide apneic oxygenation during laryngoscopy and intubation, ${ }^{129}$ although to avoid hazardous gastric insufflation, airway patency must be assured. Use of high-flow nasal oxygenation (HFNO) devices running high flows under a tightly sealed mask should be avoided, e.g., during FMV, for fear of rapid gastric distention or pulmonary hyperinflation and subsequent barotrauma.

- High risk of oxygen desaturation due to refractory hypoxemia: The critically ill patient with substantial lung parenchymal disease and high shunt fraction is often refractory to pre-oxygenation and apneic oxygenation techniques, resulting in severely limited safe apnea time. The use of awake intubation and HFNO while maintaining spontaneous ventilation is one option to help address this scenario, if feasible.

The benefit of de-nitrogenation/pre-oxygenation is age dependent. Children have a relatively low FRC and high metabolic demand, which combine to create short apnea times despite pre-oxygenation. They often benefit from apneic oxygenation techniques to help maintain oxygenation during airway management. ${ }^{130}$

The CAFG recommends universal pre-oxygenation before the induction of general anesthesia/rapid-sequence intubation (RSI), if feasible.

\subsubsection{Apneic oxygenation}

The use of apneic oxygenation can be beneficial in prolonging the safe apnea time during airway management. Apneic oxygenation is most often 
accomplished with the use of standard nasal cannulae at flows of 5-15 L.min ${ }^{-1}$ or devices that provide heated and humidified oxygen at higher flows $\left(40-70 \mathrm{~L} \cdot \mathrm{min}^{-1}\right.$ in adults-i.e., HFNO). Apneic oxygenation is thought to work by a number of synergistic mechanisms, including mass flow of oxygen along a pressure gradient from the pharynx to the alveoli, turbulent supraglottic flow vortices and dead space flushing, as well as the effect of cardiac oscillations on intrathoracic pressure. ${ }^{131-134}$ Nevertheless, the airway manager must recognize that while oxygenation might be maintained, carbon dioxide clearance will be diminished during apneic oxygenation. Thus, caution and monitoring are required when allowing prolonged apnea in all patients, but especially those with increased intracranial pressure, metabolic acidosis, or pulmonary hypertension. $^{132}$

Apneic oxygenation by both standard nasal cannulae and HFNO has been studied in operating room (OR), emergency department (ED), and intensive care unit (ICU) settings. In general, compared with no apneic oxygenation, use of apneic oxygenation is effective in reducing oxygen desaturation during laryngoscopy in both adult and pediatric surgical patients. ${ }^{132,135-141}$ Results are mixed in out-of-OR settings such as the ED or ICU, possibly relating to factors such as patient population (e.g., shunt physiology precluding oxygen uptake) or study design (e.g., a nonpatent airway during apnea before laryngoscopy). ${ }^{132,142-150}$

The CAFG recommends that at a minimum, apneic oxygenation should be used for patients with anticipated difficult or prolonged laryngoscopy/tracheal intubation and/or for the patient with anticipated intolerance of apnea. It is essential to note that apneic oxygenation relies on a patent upper airway and will have no effect if the airway is obstructed.

\subsubsection{Maintenance or ablation of spontaneous ventilation?}

General anesthesia with maintenance of spontaneous ventilation has been suggested to facilitate tracheal intubation when difficulty is anticipated. Nevertheless, despite the theoretical safety advantage afforded by the maintenance of inspiratory effort, ${ }^{151}$ functional upper airway obstruction can occur with loss of consciousness, to a greater degree than occurs during natural sleep. ${ }^{152}$ This follows from attenuation of upper airway dilator muscle activity, which makes the pharynx vulnerable to collapse. $^{153,154}$ The tendency of an airway to collapse with loss of consciousness is compounded by the negative intraluminal pressures generated during spontaneous inspiration within a narrowed airway. ${ }^{153}$ Although inhalational induction is commonly used in pediatric patients, in adults it can take considerable time to reach a plane of general anesthesia sufficiently deep to allow for airway instrumentation without provoking reflex glottic closure. The NAP4 report highlighted the hazards of using inhalational induction in the adult patient with obstructing airway pathology. ${ }^{1}$ The CAFG does not endorse use of inhalational induction of general anesthesia as a sole strategy for the adult patient with anticipated difficult laryngoscopy or tracheal intubation.

\subsubsection{Assessing for FMV efficacy prior to administration of a neuromuscular blocking agent}

After the induction of general anesthesia, a trial of FMV prior to administering neuromuscular blocking agents (NMBAs) has been advocated, ${ }^{155}$ with a view to potentially allowing the patient to awaken if FMV is unsuccessful. Nevertheless, in this situation, the effect of sedative-hypnotics may not dissipate or be reversible in sufficient time for the patient to resume spontaneous ventilation before significant hypoxemia occurs. ${ }^{156}$ Thus, the more appropriate action when impossible FMV occurs would be to proceed with tracheal intubation or SGA insertion, both of which will be facilitated by neuromuscular blockade. ${ }^{157-159}$ Studies of pharmacologic paralysis (albeit almost always having been performed in patients without difficult airways) generally conclude that pharmacologic paralysis facilitates FMV, and virtually never makes it worse. ${ }^{160-167}$ With or without anticipated difficulty, if electing to proceed with tracheal intubation after the induction of general anesthesia, the CAFG did not find sufficient evidence to support a recommendation for a trial of FMV prior to NMBA administration.

\subsubsection{Use of short or intermediate-acting neuromuscular blockade}

When difficulty with tracheal intubation is anticipated, the CAFG could not find evidence of an outcome benefit to justify recommending use of succinylcholine over an intermediate-acting non-depolarizing NMBA. Considerations in choosing a NMBA include the following:

- Pharmacologic modelling studies have indicated that succinylcholine may not necessarily wear off in time to allow resumption of spontaneous ventilation before hypoxemia occurs in the CVCO situation. ${ }^{168,169}$ In addition, the residual effects of the sedative/induction agent may persist, also impairing a return to adequate spontaneous ventilation.

- Similarly, a proportion of patients given sugammadex for reversal of rocuronium or vecuronium would also critically desaturate during the time required to draw up and administer the drug and for it to work, particularly if apnea intolerant. ${ }^{169}$ In one simulation study of a 
CVCO situation, ${ }^{170}$ a substantial time passed from a decision to use the drug, obtaining it, and its administration to the patient. Therefore, the immediate availability of sugammadex is recommended in all airway management locations. It should be noted that sugammadex will not necessarily reverse $\mathrm{CVCO}$ situations related to obstructing airway pathology. ${ }^{171,172}$

- In critically ill patients where airway management is being performed as part of a resuscitation, expectations of a return to effective spontaneous ventilation is unrealistic when the clinical trajectory is rapidly deteriorating. Use of succinylcholine or a plan to reverse rocuronium if difficulty occurs is not a reliable plan if it is the only difficult airway strategy being deployed.

- Use of an intermediate-acting NMBA to facilitate tracheal intubation will optimize conditions for the duration of airway management should more than one attempt be required, including change of device or operator.

\subsubsection{Choice of equipment}

Resources allowing, the CAFG advocates for the routine use of VL (with appropriately selected blade type) for tracheal intubation, with or without anticipated difficulty. ${ }^{5}$ Regardless of the chosen technique, the airway manager must attain and maintain competence with its use in lower acuity clinical or simulation settings. ${ }^{173,174}$

\subsubsection{Difficulty encountered with a first attempt at tracheal intubation}

Difficulty with tracheal intubation after the induction of general anesthesia will inevitably occur from time to time, whether predicted or not. The reader is referred to the accompanying part $1 \operatorname{article}^{5}$ for recommendations on management of this situation.

\subsection{Difficult tracheal intubation predicted-other options}

When difficult tracheal intubation is predicted, most patients will be intubated either awake or after the induction of general anesthesia with additional preparation and precautions. Nevertheless, in some circumstances, the following options may be considered:

\subsubsection{Avoiding predicted difficult tracheal intubation-use of regional or local anesthesia for a surgical case}

When difficult tracheal intubation is predicted, some surgical cases may be amenable to regional or local anesthesia, with the following caveats:

- As complications from the surgical procedure itself, administered local anesthetic or sedative medications could all present the need for airway management despite the use of a regional technique, a complete airway evaluation must still occur, and a management strategy determined.

- The surgical procedure must be of a predictable duration, and the block must be shown to be effective before proceeding.

- Ideally, there should be easy access to the patient's airway intraoperatively.

- Before proceeding, the team should be briefed on the patient's difficult airway status, together with the plan for intraoperative airway management if needed.

\subsubsection{Deferring management of the patient with predicted difficult tracheal intubation}

Occasionally, it might be appropriate to defer airway management when difficult tracheal intubation is predicted. Examples of this include:

- Transferring an elective surgical patient to a more fully equipped hospital;

- Transferring a pediatric surgical patient with known facial dysmorphism to a specialized pediatric hospital for management;

- Rescheduling a semi-urgent surgical procedure from overnight hours until daytime staff have arrived;

- Deferring tracheal intubation of a critically ill patient by temporizing with the use of non-invasive ventilation or HFNO while additional expertise and equipment is sourced, or until the patient is transferred to a different location (e.g., the OR) for the intubation.

\subsubsection{Use of an SGA in the patient with known or predicted difficult tracheal intubation}

For the patient with predictors or a history of difficult tracheal intubation, the use of an SGA requires careful consideration. Three scenarios that might be considered include:

- For the case normally undertaken with tracheal intubation, electively choosing to proceed with an SGA simply to avoid a difficult tracheal intubation 
situation has been shown to be hazardous. ${ }^{1}$ The CAFG recommends against this practice. Rather, the difficult intubation situation should be safely dealt with "up front".

- For a case where an SGA would normally be used, using an SGA in a patient with anticipated difficult tracheal intubation is often successful, although the airway manager must recognize that the fallback option of defaulting to tracheal intubation should the SGA fail may not easily succeed. This might suggest consideration of initial tracheal intubation as the safer plan when general anesthesia is required. If using an SGA regardless, at the very least, there should be a predetermined plan for airway management should SGA ventilation fail.

- Despite the above, SGA use is often (appropriately) recommended as a fallback option after failed tracheal intubation in the induced patient. ${ }^{5,6}$ The SGA can be used to maintain oxygenation and temporize the situation pending the patient's awakening, while obtaining more equipment or expertise, or it might be used as a conduit to facilitate FB-aided intubation. In an urgent situation (e.g., failed tracheal intubation during emergency Cesarean delivery under general anesthesia), a risk to benefit analysis might justify continuing with the SGA.

\section{Special situations}

\subsection{The patient with a known or suspected highly} infectious respiratory pathogen

Airway management guidelines for patients with known or suspected highly transmissible infections should follow core principles, with some modification. The contemporary experience of the COVID-19 pandemic caused by SARSCoV-2 infection is but one example that may lead to respiratory failure requiring tracheal intubation. ${ }^{175}$

- Team safety. The risk of transmission of a highly infectious pathogen such as SARS-CoV-2 to a healthcare worker in the immediate peri-intubation period depends on the pathogen and precautions taken. ${ }^{176,177}$ Spread for most pathogens is assumed to occur by direct contact with droplet containing viral particles, and/or from aerosols generated during a patient cough or an airway procedure (i.e., aerosolgenerating medical procedure [AGMP]). Whether it is an elective surgical patient who has tested positive for a highly infectious pathogen, a critically ill patient with unknown status, or a patient requiring tracheal intubation because of primary respiratory disease caused by a highly infectious pathogen, airway manager and team safety is paramount. Hastening to manage one of these patients without considering team safety may result in healthcare worker infections. The number of people in the room should be kept to a minimum, with a pre-assigned primary airway manager, an airway assistant, and ideally a third clinical support practitioner.

- Personal protective equipment (PPE). While there has been significant controversy surrounding what defines "safe" PPE for practitioners caring for patients infected by a highly infectious pathogen, it remains possible that airway management poses a significant potential risk for clinicians. ${ }^{178}$ During airway management involving AGMPs, an important risk period occurs while removing (doffing) PPE. Incorrectly donning PPE or using inadequate PPE also poses a risk to the airway manager. Airborne, contact, and droplet precaution PPE for practitioners directly performing or assisting in airway management includes an N95 respirator, eye shield, Association for the Advancement of Medical Instrumentation level 3 gown, neck cover, and gloves. ${ }^{176,178}$ Training in donning and doffing PPE should be performed regularly and practitioners should be checked to ensure adequate PPE coverage before entering the patient care room.

The CAFG recommendations for airway management of the patient with a known or suspected respiratory infectious disease spread by droplet or airborne mechanism reflect other published consensus statements on the topic ${ }^{179-184}$ and are summarized in Table 10.

\subsection{The patient with obstructing airway pathology} or a traumatized airway

The patient with known or suspected obstructing airway pathology, or with airway trauma, requires careful and skilled evaluation and planning. Obstructing pathology can occur from tumour, infection, edema, foreign body, or stenosis. Trauma can distort the expected anatomy and might involve a breach of integrity of the airway, sometimes in more than one location. If general anesthesia has been induced and the patient is apneic, patients in both categories may present significant technical difficulties with some or all of DL or VL, FMV and SGA use. When tracheal intubation is indicated and time and resources permit, enhancing the standard airway evaluation is advised. Patient cooperation allowing, nasal endoscopic evaluation of the pharynx and larynx will help clarify the nature and extent of glottic and supraglottic pathology or injury. ${ }^{19}$ Any available computed tomography or magnetic 
Table 10 Airway management considerations for the patient with known or suspected respiratory infectious disease spread by droplet or aerosol

CAFG recommendations for airway management of the patient with known or suspected highly infectious respiratory infectious disease spread by droplet or airborne mechanism

Environment and preprocedure

Equipment

Pre-oxygenation

Induction

Intubation Unanticipated difficult
airway

\section{CVCO and eFONA}

- If out of the operating room/theatre, an airborne infection isolation room is preferred for tracheal intubation.

- A negative pressure environment is preferred regardless of location, but ventilation rate/air exchanges are more important than positive or negative pressurization.

- Minimize team members in the room. The most experienced available airway manager should perform tracheal intubation.

- Supervised personal protective equipment (PPE) donning should occur.

- Perform team briefing; use a checklist.

- Simulation-based team training is valuable.

- Place a viral filter between tracheal tube, face mask, or supraglottic airway (SGA) and more proximal ventilation equipment.

- Sidestream capnography aspiration to be located proximal to the viral filter.

- Use video laryngoscopy as primary technique:

To increase first-pass success

To avoid close proximity to patient's face and respiratory tract

To enable a shared mental model and situation awareness of non-intubating team members.

- Consider using SGAs for airway rescue scenarios only—not as a planned technique. Second-generation devices are recommended for their higher seal pressures.

- Take pre-packaged kits with required equipment into the room.

- Position a standby airway cart (+/- additional personnel in PPE as "runners") outside room.

- Pre-oxygenate with a well-applied face mask.

- Add PEEP valve to bag-valve mask set-up, if using.

- Limit flow rates to the least required to obtain desired fraction of exhaled oxygen value (e.g., 0.9). This may not always be achievable.

- Intravenous induction with NMB preferred.

- FMV discouraged while awaiting onset of NMB unless clinically significant hypoxemia has occurred or is expected.

- Avoid apneic oxygenation with HFNO.

- If apneic oxygenation is used, consider use of low oxygen flows (e.g., $5 \mathrm{~L} \mathrm{~min}^{-1}$ ).

- Most experienced airway manager available should manage the airway.

- Ensure a styleted tracheal tube or bougie is available, as appropriate to the video laryngoscope blade in use.

- Institute positive pressure ventilation only after tracheal tube cuff inflation.

- If high airway pressures are encountered, ensure tracheal tube cuff pressure is $5 \mathrm{~cm} \mathrm{H}_{2} 0$ higher than peak inspiratory pressure.

- Use FMV between intubation attempts only if needed to re-oxygenate the patient.

- If FMV is undertaken, use two-handed mask application with thenar eminence ("V-E") grip to maximize seal and jaw lift effectiveness.

- Use waveform capnography to confirm efficacy of rescue ventilation.

- Avoid excessive ventilation. Respiratory rate, volume and inspiratory pressure should ideally be guided by objective feedback (waveform capnography, pressure manometer).

- For the elective surgical patient, if SGA rescue is used, consider using a second-generation device that supports FB-aided tracheal intubation.

- If SGA rescue has occurred, then patient awakening is preferred: if not feasible, other options include FB-aided intubation through the SGA, or FONA during SGA-supported ventilation. Proceed with surgery only if considered safe.

- Above all, the safety of the team must be prioritized.

- Scalpel-bougie emergency FONA is the recommend technique.

- Transiently discontinue attempted FMV or SGA ventilation during incision of cricothyroid membrane. 
Table 10 continued

\begin{tabular}{ll}
\hline $\begin{array}{l}\text { Awake tracheal } \\
\text { intubation }\end{array}$ & - Avoid awake intubation unless high risk of a CVCO situation with induction of general anesthesia/RSI. \\
- VL or flexible bronchoscopy can be used for awake tracheal intubation, skills allowing. Consider use of an SGA \\
as a conduit for the FB. \\
- Consider alternatives to local anesthetic nebulization or aerosolization for topical airway anesthesia, e.g., local \\
anesthetic gels/ointments or nerve blocks. \\
- Avoid circuit disconnections. \\
- Place ventilator into standby mode if disconnection is needed. \\
- Disconnect circuit proximal to viral filter if feasible; if not, then consider temporarily clamping the tracheal tube, \\
- Seeking to avoid damaging it or its pilot line. \\
- Tracheal extubation is an AGMP with potentially higher risk for aerosol generation than intubation ${ }^{185}$. \\
- Use pharmacologic measures to help prevent cough, agitation, or vomiting during or after extubation. \\
- Place a surgical or procedure mask on the patient before awake extubation and extubate while the mouth, nose, \\
and nasal prongs are covered by the mask; leave the mask on the patient during subsequent transfer ${ }^{186}$. \\
- Avoid airway exchange procedures if possible. \\
- Dispose of airway management equipment appropriately. \\
- Doff PPE under supervision.
\end{tabular}

AGMP = aerosol-generating medical procedure; $\mathrm{CAFG}$ = Canadian Airway Focus Group; CVCO = cannot ventilate, cannot oxygenate; eFONA $=$ emergency front of neck airway access; FB = flexible bronchoscope; FMV = face-mask ventilation; FONA = front of neck airway access; NMB = neuromuscular blockade; $\mathrm{PEEP}=$ positive end-expiratory pressure; $\mathrm{PPE}=$ personal protective equipment; RSI = rapid-sequence intubation; SGA = supraglottic airway.

resonance imaging scans should also be reviewed, especially for patients with pathology below the glottis, recognizing that for dynamic pathology, any imaging occurs at an unknown point in the patient's respiratory cycle. $^{20}$

Planning a safe approach to tracheal intubation of these patients should occur according to the principles described in Section 6 above, in consultation with all involved team members, including the surgical team. If difficulty is anticipated with two or more of tracheal intubation, FMV, and SGA ventilation, an awake approach (via a nasal, oral, or front of neck route) is advised.

The trauma patient with a blunt or penetrating injury to the airway must be assessed for how best to approach airway management, as well as for the potential for vascular or other injury. Patient cooperation and time allowing, securing the airway awake during spontaneous ventilation (e.g., by awake tracheotomy or awake oral or nasal intubation) enables avoidance of positive pressure ventilation above the level of a known or suspected airway breach, and its attendant risk of causing or exacerbating pneumothorax, pneumomediastinum or subcutaneous emphysema. There is also the potential for entering a tear, creating a false passage, or converting a partial tracheal disruption to a complete disruption during tracheal intubation. Thus, indirect visualization of the anatomy (e.g., using a FB until distal to the suspected or known level of breach) is recommended. Management of the traumatized airway has recently been well reviewed. ${ }^{187}$
Successful use of an SGA as a primary technique has been described under combat conditions, ${ }^{188}$ as well as in surgical patients with obstructing pathologies. ${ }^{189}$ Such reports are limited to observational case series or single case reports; randomized-controlled trials are lacking. Thus, while an SGA might successfully rescue a failed intubation, the CAFG recommends securing the obstructed or traumatized airway by tracheal intubation or FONA, when resources allow. As indicated in section 7.1.6, some severe cases of obstructing pathology below the thoracic inlet might be most safely managed with institution of ECMO before the airway is managed. Multidisciplinary planning and management are required.

\subsection{The morbidly obese patient}

The obese patient is at elevated risk during airway management. The NAP4 audit reported that patients with a body mass index $(\mathrm{BMI})>30 \mathrm{~kg} \cdot \mathrm{m}^{-2}$ were twice as likely to suffer a severe airway complication, and those with BMI $>40 \mathrm{~kg} \cdot \mathrm{m}^{-2}$ (morbidly obese) were four times as likely. ${ }^{1}$ Patients were obese in $68 \%$ of difficult intubation claims in a recent analysis of the Anesthesia Closed Claims Project database. $^{2}$

A higher BMI is associated with difficult FMV. ${ }^{25,28,40,45-48}$ A co-existing thick neck ${ }^{40-42}$ (e.g., circumference $>40-50 \mathrm{~cm}$ ), obstructive sleep apnea (OSA), ${ }^{25,40,43,46,167}$ and/or a history of snoring $39,45,47,48$ are also associated with difficult FMV. A thick neck $^{15,28,190-192}$ and OSA $^{167}$ are associated with difficult 
DL or intubation. Whether obesity alone predicts difficult laryngoscopy/intubation continues to be controversial, with some studies reporting an association,,$^{15,29,31,39,192-195}$ and others not. ${ }^{1,25,191,196-198}$ No studies have yet reported obesity to be a risk factor for difficult or failed VLfacilitated tracheal intubation, although one study has reported a thick neck to be associated with failed HA-VLfacilitated tracheal intubation. ${ }^{33}$ In another study, a higher neck skinfold thickness was associated with longer times to successful intubation with a FB in anesthetized patients. ${ }^{38}$ Obesity or a thick neck also predicts difficulty with SGA use in some, ${ }^{49-51}$ but not all ${ }^{199}$ studies, and may predict difficulty with palpation of landmarks for eFONA.

Even more significant are physiologic challenges during airway management of the obese patient. ${ }^{53}$ With reduced FRC, apnea is poorly tolerated, so that if difficulty is encountered in establishing ventilation, rapid oxygen desaturation must be anticipated.

Canadian Airway Focus Group recommendations for airway management of the obese and morbidly obese patient are as follows:

- The potential for technical difficulty with both tracheal intubation and other modes of ventilation, coinciding with likely apnea intolerance, suggests that the airway manager should carefully consider whether ATI might confer a safety benefit (Fig. 1).

- Regardless of the chosen approach, close attention to patient positioning is recommended, with ramping to ensure the patient's tragus is aligned with the sternum. ${ }^{96,98}$ "Back up" or reverse Trendelenburg positioning will help delay oxygen desaturation. ${ }^{116-124}$ If general anesthesia is elected, careful pre-oxygenation must occur, with a goal of achieving $\mathrm{FeO}_{2} \geq 0.9$.

- Apneic oxygenation is recommended during laryngoscopy and intubation of all morbidly obese patients when managed after the induction of general anesthesia.

- Given the anticipated short apnea time and potential for difficulty with fallback ventilation options, primary use of VL (with appropriately selected blade type) is recommended for tracheal intubation to help maximize first-pass success.

- Careful planning and documentation should occur before embarking on airway management of the obese patient. The team should be briefed on the strategy in the event that difficulty is encountered; this should include the triggers for moving to the next step in the plan. Given the potential for rapid oxygen desaturation, the airway manager should consider having a second experienced airway manager stand by for assistance if required.
8.4 The patient with an increased risk of aspiration

In the NAP4 audit, aspiration was the most common cause of airway management-related death and brain damage. ${ }^{1}$ In an incident-reporting study from Australia and New Zealand, aspiration was associated with significant harm, with many of the cases occurring in fasted patients. ${ }^{200} \mathrm{In}$ the difficult airway patient, the risk of aspiration increases in conjunction with the potential for longer or multiple intubation attempts and/or gastric insufflation with FMV between attempts. ${ }^{201-203}$

Tracheal intubation is indicated when general anesthesia is required in the at-risk patient. Although secondgeneration SGAs with integrated drainage ports may confer some protection against aspiration, ${ }^{204}$ neither an SGA or FMV would typically be used as an intended primary technique in this scenario. Nevertheless, these modalities can and should be used as needed to maintain oxygenation between intubation attempts.

Although better referred to as "cricoid force", cricoid pressure (CP) applied with a force of $10 \mathrm{~N}$ (i.e., $1 \mathrm{~kg}$ ) before induction and $30 \mathrm{~N}$ (i.e., $3 \mathrm{~kg}$ ) after loss of consciousness may reduce the risk of regurgitation and hence aspiration during RSI by occluding the hypopharynx behind the cricoid cartilage. ${ }^{205}$ Nevertheless, especially if poorly applied, $\mathrm{CP}$ can also make tracheal intubation more challenging, ${ }^{206}$ and it can also complicate SGA insertion. Evidence on the effectiveness of $\mathrm{CP}$ has been conflicting ${ }^{207}$ and controversial, creating equipoise around its use. Birenbaum et al. recently published a large randomized non-inferiority trial ( $n=3,472$ at-risk patients) on the use of $\mathrm{CP}{ }^{208}$ The primary outcome of aspiration did not differ between the actively applied CP (ten cases; $0.6 \%$ ) and sham CP (nine cases; $0.5 \%$ ) groups (relative risk of aspiration for the sham $\mathrm{CP}$ group compared with the actual CP group 0.9; $90 \%$ confidence interval, 0.39 to 1.99 ). In addition, glottic visualization and duration of intubation favoured the sham CP group. Despite the clinically equivalent occurrence of aspiration between groups, methodologically, the authors were unable to declare non-inferiority of sham CP because of a lower-thanexpected aspiration event rate. Other study limitations included the non-inclusion of obstetric, critical care, and ED patients, and there were few $(<1 \%$ of the total) subjects with an anticipated difficult airway. Nevertheless, given that the original Sellick communication on $\mathrm{CP}$ was a small, non-randomized, unblinded, uncontrolled case series of 26 patients, ${ }^{209}$ having the very large Birenbaum et al. study suggest no clinically important difference in the incidence of aspiration in an at-risk population is very helpful in advancing our understanding of CP.

Canadian Airway Focus Group recommendations for airway management of the patient with an anticipated 
difficult airway and an increased risk of aspiration are as follows:

- There may still be a role for correctly applied CP in some settings (e.g., obstetrics). Given the limited data available, the ultimate decision to use $\mathrm{CP}$ is at the discretion of the airway manager;

- When a significantly elevated risk of aspiration coincides with an anticipated difficult airway, performing ATI with minimal sedation may confer a safety benefit;

- If the airway manager decides to intubate the at-risk patient after the induction of general anesthesia, practical advice includes suctioning a nasogastric tube if already present (consider inserting one if not) before induction, placing the patient in the back up or reverse Trendelenburg position, and having two suction devices immediately available for oropharyngeal suctioning. Before induction, an in situ nasogastric tube should be attached to continuous low-pressure suction to prevent intra-gastric pressure accumulation following induction $^{210}$;

- Use of VL allows airway team members to assess the laryngeal view, the impact of CP (if used) on the view of the glottis, and provides heightened situational awareness during a critical time. Nevertheless, should massive regurgitation occur, the camera may be obscured. Thus, unless difficulty in glottic visualization is anticipated, use of Mac-VL is preferable in the patient at high risk of regurgitation, to allow direct, eye-to-glottis visualization if necessary;

- If CP is deemed to be impeding either laryngoscopy or tracheal intubation, it should be removed;

- The use of FMV with low inspiratory pressure during RSI, before or between attempts at tracheal intubation, can extend safe apnea time without oxygen desaturation;

- If the planned tracheal intubation attempts fail, a second-generation SGA should be inserted, and the integrated drainage port used to drain the esophagus. If $\mathrm{CP}$ had been applied, it should be removed for insertion of the SGA and not reapplied.

\subsection{The patient with a bleeding upper airway}

Bleeding in the upper airway and subsequent problems with airway management are important causes of airwayrelated morbidity and death. ${ }^{211-213}$ Bleeding in the upper airway is fundamentally different from other challenging airway situations in that flexible bronchoscopic and videolaryngoscopic intubation are often more difficult or impossible because of soiling with blood. In addition, because the stomach may be filled with blood, the use of an
SGA is only suitable as a temporary measure, or as a guide to intubation. ${ }^{213,214}$

Initial therapeutic measures include compression of the bleeding site, patient positioning (the patient will often only tolerate the sitting position), suctioning, oxygen delivery, and fluid resuscitation. Concomitantly, the airway should be evaluated for predictors of difficult or impossible DL, and the location of the CTM should be established. If laryngoscopy and intubation is predicted to be otherwise technically easy and the CTM is identified with certainty, then RSI can be employed, with two large bore rigid suction catheters ready. Otherwise, preparations should be made for an ATI with alternative techniques that can be used even if visibility of the airway is obscured by blood. ${ }^{213}$ Such techniques include awake FONA, awake FB-guided intubation via an SGA as well as awake DL or Mac-VL, awake retrograde-, blind nasal-, oral digital-, lighted stylet-, and ultrasound-guided intubation. ${ }^{213}$ Awake intubation with a FB or VL can still be attempted in this situation, but might fail, so the airway manager should be prepared to use one of the alternatives mentioned above. In addition, a "double set-up" to allow for eFONA should be prepared (Table 8) in case the airway is lost during attempted management.

Management of the bleeding airway has recently been reviewed in detail. ${ }^{213,215}$

\section{Tracheal extubation}

Published audits and closed legal claims continue to document the risks associated with tracheal extubation. Re-intubation in the ICU after failed extubation and tracheal tube exchange in the patient with a difficult airway have also caused patient morbidity. ${ }^{1-3,216,217}$ Although such cases consistently account for up to $25 \%$ of total airway management-related morbidity, a substantially smaller proportion of all published articles on airway management relate to tracheal extubation, rather than intubation. ${ }^{2}$ Fortunately, excellent guidelines ${ }^{218}$ and narrative reviews ${ }^{219,220}$ on tracheal extubation have been published. Intentional extubation is elective and thus allows for careful planning to occur (Fig. 2), including identification of at-risk patients after tracheal extubation.

\subsection{The at-risk tracheal extubation}

The patient may be deemed at risk at the time of tracheal extubation in one or both of two ways: 1) failure to tolerate tracheal extubation, where the patient is at risk of failing to maintain gas exchange, airway patency, or airway protection after extubation; and 2) if tracheal reintubation might be difficult, either because the patient 


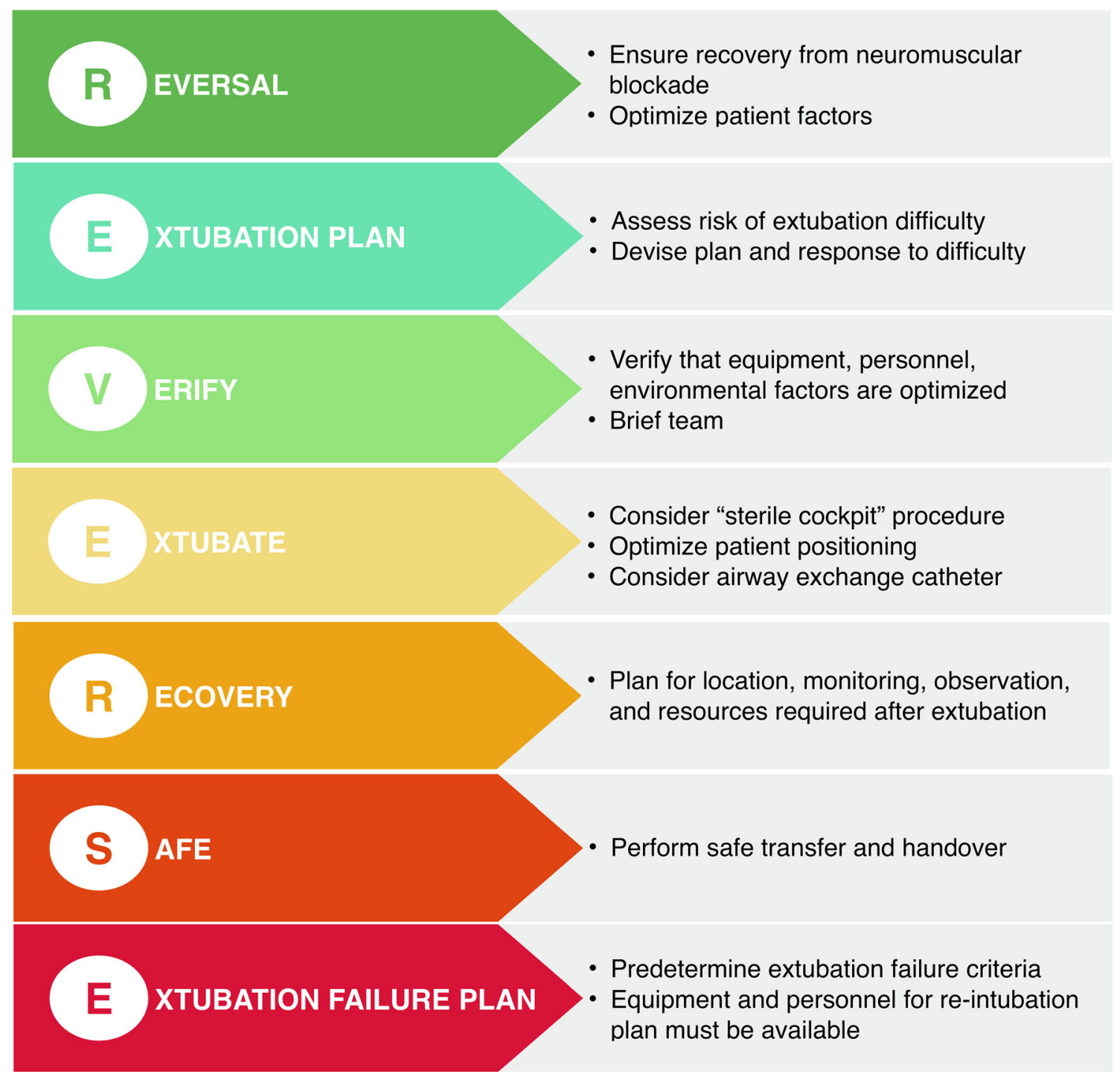

Fig. 2 Considerations for planning for safe tracheal extubation.

was originally difficult to intubate, or because of an interval event (Table 11).

In some cases, more objective risk stratification can occur before planned tracheal extubation. For example, the patient considered at risk of supraglottic or glottic airway edema might be assessed with a cuff leak test. ${ }^{221,226-228}$ In a recent systematic review, the authors concluded that the absence of a cuff leak in an at-risk patient is associated with post-extubation stridor or need for re-intubation, but the presence of a leak does not necessarily rule out the occurrence of stridor or need for re-intubation. ${ }^{228}$ Further assessment of the at-risk patient can occur by indirect visual evaluation of the glottis and supraglottic area using a $\mathrm{VL}^{229}$ or FB before emergence from anesthesia or sedation begins.

Strategies to manage the at-risk patient upon tracheal extubation are presented in Table 12.

\subsection{Lower risk ("routine") tracheal extubation}

Even for the patient not identified as being at risk of morbidity, care must be taken with tracheal extubation. Routine extubation measures such as gas exchange and hemodynamics should be adequate and level of consciousness sufficient to enable airway patency and protection. The patient's neuromuscular function, temperature, and acid-base status should be near normal. Prior to extubation, the patient should be pre-oxygenated and the pharynx should be suctioned, especially if at risk of pooled pharyngeal blood, to avoid the potential of aspirated blood forming an occluding clot in the trachea. ${ }^{2}$ Extubation at end-inspiration will help avoid immediate aspiration of blood or residual secretions. Additional CAFG recommendations for tracheal extubation are as follows: 
Table 11 Potential causes of an at-risk extubation

\section{Potential causes for an at-risk tracheal extubation}

Potential causes of failure to tolerate tracheal extubation

- Functional airway obstruction and/or inadequate management of secretions, due to:

Skeletal muscle weakness from residual neuromuscular blockade or intrinsic neuromuscular disease

Pre-existing obesity or OSA combined with opioids, residual anesthetics, or other sedative agents

$\bigcirc$ Impaired neurologic status or excess drowsiness.

- Anatomic airway obstruction from:

Airway edema, due to:

- Prolonged prone or Trendelenburg intraoperative positioning;

- Known traumatic or multiple attempts at tracheal intubation;

- Administration of large volumes of crystalloid fluid;

Residual edema after tracheal intubation for neck hematoma or airway infection; ${ }^{217}$

- In ICU patients, prolonged intubation, large tracheal tube diameter, female sex, unplanned extubation; ${ }^{221}$

- Pre-existing edema (e.g., burns or neck radiation).

$\bigcirc$ Extrinsic airway compression, e.g., due to neck hematoma, mediastinal mass

Airway obstruction from secretions or blood

Tracheal collapse, (e.g., tracheomalacia after goitre excision or prolonged intubation)

$\bigcirc$ Laryngospasm

$\bigcirc$ Unilateral or bilateral vocal cord paresis or paralysis

$\bigcirc$ Cervical spine pre-vertebral swelling ${ }^{222}$

Surgical occipital-cervical fixation in excess flexion ${ }^{217,222-224}$

Multi-level cervical spine fusion ${ }^{225}$

- Cardiopulmonary issues (especially in ICU):

$\bigcirc$ Respiratory failure due to non-resolution of an underlying problem

$\bigcirc$ Compromised functional residual capacity from obesity, gastric distension with air, incisional pain, or other reason

$\bigcirc$ Atelectasis; pneumothorax

$\bigcirc$ Advanced chronic obstructive pulmonary disease

Left or right ventricular dysfunction

Fluid overload.

- Other perioperative issues including hypothermia, altered acid-base status and uncontrolled pain.

Potential causes of difficult tracheal re-intubation

- The original tracheal intubation was difficult.

- Interval development of airway edema.

- Anatomic changes as a result of a surgical intervention:

Upper airway surgery

Upper cervical spine fusion.

- Applied mechanical constraints, including:

Intermaxillary fixation

$\bigcirc$ Halo jacket.

$\mathrm{ICU}=$ intensive care unit; OSA = obstructive sleep apnea
- As extubation of the surgical patient is often accompanied by airway manager fatigue and team distraction, a "sterile cockpit" concept of minimizing non-essential conversation during emergence and extubation of the surgical patient is advocated.

- Supplemental oxygen delivery should occur during transportation of all recently extubated patients to highdependency nursing units including postanesthesia care units. Pulse oximetry monitoring should also be used. Handover should routinely detail the type and ease of airway management.

- In critical care or ED settings, if a consulting service has recommended tracheal extubation of an intubated patient, direct communication should occur between that service and critical care/ED attending staff about the rationale and timing of extubation. Documentation of intubating conditions/difficulty should be clearly available to consulting services to help guide the extubation plan.

\subsection{Extubation over an airway exchange catheter} (AEC)

If tracheal intubation was or might now be challenging, short-term use of an AEC can be considered at extubation to assist re-intubation should it be required. Appropriately positioned and secured above the carina (e.g., at around 23 $\mathrm{cm}$ at the teeth in the adult patient), 11- or 14-French airway exchange catheters are reasonably well tolerated ${ }^{236}$ and permit spontaneous ventilation, coughing, and talking. Although AECs can support oxygen insufflation and even jet ventilation, barotrauma and fatalities have been reported in these scenarios. ${ }^{237-239}$ Conventional methods of oxygen delivery such as face mask, nasal cannula, or $\mathrm{HFNO}^{237}$ can still be used when an AEC is present; the CAFG recommends against any routine oxygen administration through an AEC. If unavoidable during an emergency, oxygen insufflation through an AEC should be limited to 2 $\mathrm{L} \cdot \mathrm{min}^{-1}$, only as a temporizing measure until oxygenation is re-established by a conventional mode of delivery, ${ }^{237}$ and close attention must be paid to ensuring that gas egress can occur. ${ }^{240}$

An AEC can be left in situ after extubation of the difficult airway patient until the need for tracheal reintubation becomes unlikely. Although case specific, in one published ICU series, most patients requiring tracheal reintubation over an AEC underwent the procedure within two to ten hours after extubation. ${ }^{236}$ The surgical patient will almost always have the AEC removed before leaving the post-anesthetic care unit. Although infrequently required, tracheal re-intubation over an AEC will be facilitated by the use of VL to both retract the tongue and 
Table 12 Strategies to address the at-risk patient upon tracheal extubation

Strategies to address the at-risk patient upon tracheal extubation Strategies to address the risks of failure to tolerate extubation

- At risk of functional airway obstruction:

Plan a multi-modal analgesia strategy for a surgical patient to help minimize need for opioids.

$\bigcirc$ Consider continuation of ventilation in the short- or medium-term to allow full recovery from inhaled or intravenous anesthetic or sedative agents.

$\bigcirc$ Ensure recovery from neuromuscular blocking agents quantitatively; non-depolarizing agents should have recovery to a train of four $\geq 0.9$ before extubation. ${ }^{230}$ For the at-risk patient, consider use of sugammadex as a reversal agent for rocuronium or vecuronium.

Tracheal extubation awake, rather than deep.

$\bigcirc$ Extubation in a head-up or back up position.

$\bigcirc$ Early transition to CPAP mask, NIV ${ }^{231-233}$ or $\mathrm{HFNO}^{232,234}$ if indicated. If used, close monitoring must still occur after extubation, and use of these modalities must not delay re-intubation if indicated.

- At risk of airway edema:

$\bigcirc$ Consider more objective assessment of the degree of edema by use of a cuff leak test and/or indirect visualization of pharynx and larynx with VL or flexible endoscopy.

$\bigcirc$ Consider deferral of extubation pending a period of short- or medium-term ventilation with head-up positioning and/or administration of steroids. ${ }^{235}$

- Optimize cardiac, pulmonary, neurologic, acid-base and body temperature status.

- Consider whether elective tracheotomy might offer a higher margin of safety.

Strategies to address the risks of difficult tracheal re-intubation

- Extubate only with a team briefing regarding the plan for reintubation if needed.

- Consider deferral of extubation until patient condition is optimized, location is optimal, and equipment and skilled personnel are available for re-intubation if required.

- Consider extubation over a place-holder airway exchange catheter (see narrative).

- Consider whether elective surgical airway might offer a higher margin of safety.

CPAP = continuous positive airway pressure HFNO = high-flow nasal oxygenation; NIV = non-invasive ventilation; $\mathrm{VL}=$ video laryngoscopy.

enable monitoring of tracheal tube passage through the glottis. ${ }^{241}$ In addition, prior passage of an intermediate catheter (e.g., the Aintree catheter; Cook Group Incorporated, Bloomington, IN, USA) over an 11- or 14-French AEC will facilitate passage of a tracheal tube through the adult larynx by reducing the size discrepancy between the outer diameter of the catheter and the inner diameter of the tracheal tube. ${ }^{242}$
Of note, the Cook AECs (Cook Group Incorporated, Bloomington, IN, USA) are only licensed for immediate tracheal tube exchange in most countries. Therefore, leaving an AEC in situ for retaining airway access following extubation, though widely practiced, is technically an off-label application.

\section{Human factors and the anticipated difficult airway}

The NAP4 study ${ }^{1}$ and published closed legal claims ${ }^{2,3}$ have indicated that airway management misadventure was often associated with inadequate evaluation and lack of a predetermined airway strategy. That is, airway managers simply did not anticipate difficulty or failed to modify their strategy appropriately despite predicted difficulty. The airway manager must be self-aware of potential human factor pitfalls to avoid. Table 13 presents some issues together with suggested mitigating strategies.

\section{Summary and key recommendations}

Informed by publications of airway-related morbidity, ${ }^{1-3}$ guidelines should not only address management techniques for the difficult airway when encountered in the unconscious patient but also emphasize the need for detailed patient evaluation, planning, and communication. In this way, safe airway management decision-making and implementation can occur. Briefly summarized, our guiding principles and recommendations are as follows:

- Airway evaluation of the patient should always occur before embarking on airway management;

- Airway evaluation includes bedside examination seeking predictors of technical difficulty with FMV, SGA use, tracheal intubation, and eFONA. Patient physiology and contextual issues should also be assessed. Review of previous airway management records, databases, and imaging studies will contribute to a complete evaluation. Nasopharyngoscopy or VL under local anesthesia can add useful information about the patient with known or suspected glottic or supraglottic pathology;

- Information gleaned from the airway evaluation must be synthesized into the safest decision on how to proceed with airway management. The use of ATI may provide an extra margin of safety when significant difficulty is predicted with VL or DL. It is also useful if difficulty is predicted with more than one mode of airway management (e.g., tracheal intubation and FMV), or predicted difficulty coincides with 
Table 13 Potential human factor issues during patient evaluation and airway management decision-making, with suggested mitigation strategies

Potential human factor issues during patient evaluation and airway management decision-making, with suggested mitigation strategies

Issue $\quad$ Possible mitigation strategies:

\begin{tabular}{|c|c|}
\hline & \multirow[b]{2}{*}{ by the airway manager } \\
\hline & \\
\hline $\begin{array}{l}\text { Failure to match planned strategy with } \\
\text { the findings of airway evaluation } \\
\text { (anatomy, physiology, and clinical } \\
\text { context) }\end{array}$ & $\begin{array}{l}\text { - Review your planned strategy for a } \\
\text { high-risk or difficult case with a } \\
\text { colleague. } \\
\text { - With predicted difficulty, before } \\
\text { proceeding, ensure that all } \\
\text { equipment for your airway strategy } \\
\text { (i.e., planned primary and fallback } \\
\text { techniques) is physically present, } \\
\text { sized for the patient, and arranged in } \\
\text { the order of anticipated use. This } \\
\text { well help ensure you have thought } \\
\text { through the situation. }\end{array}$ \\
\hline $\begin{array}{l}\text { Maintenance of competence. Use of } \\
\text { ATI is decreasing }{ }^{243} \text {. When } \\
\text { difficulty is predicted, lack of recent } \\
\text { experience, confidence, or skills in } \\
\text { ATI might tempt the airway } \\
\text { manager to avoid its use despite } \\
\text { indicators of it being the safest } \\
\text { approach. Lack of } \\
\text { suitable equipment might also be a } \\
\text { factor in some cases. }\end{array}$ & $\begin{array}{l}\text { - Enlist a colleague to help perform } \\
\text { ATI: you will both benefit from the } \\
\text { experience. } \\
\text { - Seek opportunities to perform ATIs, } \\
\text { rather than using excuses to avoid } \\
\text { them. } \\
\text { - If the patient's anatomy is amenable, } \\
\text { consider using a more familiar } \\
\text { device for ATI (e.g., VL). }\end{array}$ \\
\hline
\end{tabular}

by the assembled team

- For all patients, brief the team on your chosen strategy, including your alternate plans if the intended technique fails, together with triggers for moving to an alternate plan.

- During the briefing, specifically empower team members to speak up if they think that a trigger has occurred.

- For the patient requiring ATI with obstructing pathology, a surgeon should be physically present to perform fallback eFONA. by the organization

- The organization should mandate inclusion of the airway strategy in the first surgical safety checklist.

- Airway management education programs should include material on safe decision-making, rather than only teaching "hands-on" skills.
"Production pressure" to get a case done might lead to an unsafe decision to manage a difficult airway patient after the induction of general anesthesia, when ATI might be the safer approach.

\footnotetext{
- When sensing production pressure, (whether self-induced or from another source) push back by deliberately slowing to reflect on whether the pressure is adversely impacting your patient's safety.

- Pre-empt any pushback on planned ATI by using "safest for the patient" language.

- With significant predicted difficulty, if considering tracheal intubation after the induction of general anesthesia, as a thought exercise, satisfy yourself that it can occur with a margin of safety equal to or greater than ATI. If not, proceed with the ATI.

- Beware of "gambler's fallacy": the false belief that the outcome of the current case is less (or more) likely given results of previous events. Judge every case on its own, based on findings from the airway evaluation.
}

"Normalization of deviance 3 ": the airway manager might have managed a series of patients after the induction of general anesthesia where despite predictors of difficulty, none occurred. On the basis of thus "getting away with it" over time, inducing such patients might become a clinician's normal practice, rather than even considering ATI.
- Increase team buy-in by early communication with the surgeon and team when ATI is needed for an operative case.
- The organization should provide training and maintenance of competence workshops in ATI techniques, including use of the FB.

- Provide airway simulators or standard airway training manikins for individual practice at any time.

- Ensure equipment for all aspects of ATI is easily accessible at airway management locations.

- Package all equipment and local anesthetics needed for topical airway anesthesia together in easilyaccessed "grab kits".

- Multidisciplinary team training or rounds on adverse airway events might help improve communication and cooperation for future difficult airway situations that involve multiple specialties.
- Team members should be encouraged • Appoint a hospital "airway lead"244 to speak up if uncomfortable with in your department or hospital, the airway manager's chosen tasked with ensuring a full array of approach. The "PACE" (probe- difficult airway equipment is readily alert-challenge-emergency) or available across the institution, similar mnemonic can be used as a arranging airway education, prompt by team members to question the planned approach. including skills in ATI, and to help constructively debrief airway-related critical incidents and near-events.

ATI = awake tracheal intubation; eFONA = emergency front of neck airway access; FB = flexible bronchoscope; VL = video laryngoscopy .

significant physiologic (e.g., apnea intolerance or aspiration risk) or contextual issues;

- Awake tracheal intubation can proceed via oral, nasal, or front of neck routes. In some cases, oral or nasal ATI can be facilitated by a variety of devices (e.g., flexible bronchoscopy or VL);
- If a lack of patient cooperation or time precludes ATI, and airway management after the induction of general anesthesia must proceed, it should proceed with "double set-up" preparation allowing for immediate eFONA; 
- Management of the anticipated difficult airway after the induction of general anesthesia should only occur with an appropriate pre-determined strategy for difficulty if/ when encountered. A second airway manager should be sourced, the team briefed, and the required equipment brought to the room. Attention should be paid to patient positioning, pre-oxygenation, and apneic oxygenation;

- Regardless of the chosen approach when difficulty is predicted, the airway manager must clearly communicate the planned management strategy to the team, including the triggers for moving from one technique to the next;

- Extra care should be used in the planning and implementation of care for the patient with head and neck pathology, obesity, or increased aspiration risk;

- Tracheal extubation of the at-risk patient must be carefully planned in terms of assessing whether the patient can tolerate extubation and whether reintubation might be difficult;

- As unanticipated difficulty with airway management can occur despite none being predicted, the airway manager must be ready with a strategy for difficulty occurring in every patient, and the institution must make difficult airway equipment readily available and easily accessible;

- As pandemic conditions add complexity to both routine and difficult airway decision-making and management, individual and institutional preparedness should be mandated.

Management of difficulty with airway management occurring in the already-unconscious patient is addressed in the part 1 companion article. ${ }^{5}$

Author contributions See Appendix.

Acknowledgements The members of the CAFG thank Brooke Ballantyne Scott, MLIS for invaluable assistance in conducting literature searches for this project. In addition, we wish to express our gratitude to the following clinicians for their review of this manuscript and very helpful suggestions: Drs. Loes Bruijstens, Tim Cook, Thomas Heidegger, and Michael Kristensen.

Disclosures See Appendix.

Funding None.

Editorial responsibility This submission was handled by Dr. Hilary P. Grocott, former Editor-in-Chief, Canadian Journal of Anesthesia/Journal canadien d'anesthésie.

Open Access This article is licensed under a Creative Commons Attribution-NonCommercial 4.0 International License, which permits any non-commercial use, sharing, adaptation, distribution and reproduction in any medium or format, as long as you give appropriate credit to the original author(s) and the source, provide a link to the Creative Commons licence, and indicate if changes were made. The images or other third party material in this article are included in the article's Creative Commons licence, unless indicated otherwise in a credit line to the material. If material is not included in the article's Creative Commons licence and your intended use is not permitted by statutory regulation or exceeds the permitted use, you will need to obtain permission directly from the copyright holder. To view a copy of this licence, visit http://creativecommons.org/licenses/ by-nc/4.0/.

\section{Appendix: Author contributions and disclosures}

\begin{tabular}{|c|c|c|}
\hline Author & Contributions & Disclosure(s) \\
\hline $\begin{array}{l}\text { J. Adam } \\
\text { Law, MD }\end{array}$ & $\begin{array}{l}\text { Focus Group chair; data } \\
\text { acquisition, analysis and } \\
\text { interpretation; writing } \\
\text { and critically revising } \\
\text { article; final approval of } \\
\text { version to be published. }\end{array}$ & $\begin{array}{l}\text { Work supported by the } \\
\text { Department of } \\
\text { Anesthesia, Dalhousie } \\
\text { University. } \\
\text { Course co-director of } \\
\text { Airway Interventions } \\
\text { and Management in } \\
\text { Emergencies (AIME) } \\
\text { course and partner in } \\
\text { parent company } \\
\text { AIME Training Inc. } \\
\text { Course director of the } \\
\text { Anesthesia edition of } \\
\text { the Difficult Airway } \\
\text { Course and partner in } \\
\text { parent company } \\
\text { Airway Management } \\
\text { Education Center, } \\
\text { LLC. } \\
\text { Recipient of equipment } \\
\text { as loan or donation } \\
\text { from Verathon, } \\
\text { Ambu, Karl Storz and } \\
\text { Covidien. }\end{array}$ \\
\hline $\begin{array}{l}\text { Laura } \\
\text { Duggan, } \\
\text { MD }\end{array}$ & $\begin{array}{l}\text { Data acquisition, analysis } \\
\text { and interpretation; } \\
\text { critically revising article; } \\
\text { final approval of version } \\
\text { to be published. }\end{array}$ & $\begin{array}{l}\text { Editor of the journal } \\
\text { Anaesthesia and co- } \\
\text { creator of The Airway } \\
\text { App }\end{array}$ \\
\hline $\begin{array}{l}\text { Mathieu } \\
\text { Asselin, } \\
\text { MD }\end{array}$ & $\begin{array}{l}\text { Data acquisition, analysis } \\
\text { and interpretation; } \\
\text { writing and critically } \\
\text { revising article; final } \\
\text { approval of version to be } \\
\text { published. }\end{array}$ & None \\
\hline
\end{tabular}


Appendix continued

\begin{tabular}{|c|c|c|c|c|c|}
\hline Author & Contributions & Disclosure(s) & Author & Contributions & Disclosure(s) \\
\hline \multirow[t]{3}{*}{$\begin{array}{l}\text { Paul Baker, } \\
\text { MBChB, } \\
\text { MD }\end{array}$} & \multirow[t]{3}{*}{$\begin{array}{l}\text { Data acquisition, analysis } \\
\text { and interpretation; } \\
\text { critically revising article; } \\
\text { final approval of version } \\
\text { to be published. }\end{array}$} & \multirow{3}{*}{$\begin{array}{l}\text { Co-owner and inventor, } \\
\text { the ORSIM } \\
\text { bronchoscopy } \\
\text { simulator. Owner of } \\
\text { the AirwaySkills } \\
\text { course and recipient } \\
\text { of equipment as loan } \\
\text { or donation from } \\
\text { Fisher and Paykel } \\
\text { Healthcare, Karl } \\
\text { Storz, Verathon, } \\
\text { Ambu, Covidien, } \\
\text { Truphatec, AAM } \\
\text { Healthcare, Welch } \\
\text { Allyn }\end{array}$} & $\begin{array}{l}\text { François } \\
\text { Lemay, } \\
\text { MD }\end{array}$ & $\begin{array}{l}\text { Data acquisition, analysis } \\
\text { and interpretation; } \\
\text { critically revising article; } \\
\text { final approval of version } \\
\text { to be published. }\end{array}$ & None \\
\hline & & & $\begin{array}{l}\text { Rudiger } \\
\text { Noppens, } \\
\text { MD PhD }\end{array}$ & $\begin{array}{l}\text { Data acquisition, analysis } \\
\text { and interpretation; } \\
\text { critically revising article; } \\
\text { final approval of version } \\
\text { to be published. }\end{array}$ & $\begin{array}{l}\text { Recipient of equipment } \\
\text { for clinical trial from } \\
\text { Karl Storz, Germany. } \\
\text { Recipient of honoraria } \\
\text { from Medtronic and } \\
\text { Karl Storz for lectures } \\
\text { at Euroanesthesia. }\end{array}$ \\
\hline & & & $\begin{array}{l}\text { Matteo } \\
\text { Parotto, } \\
\text { MD, PhD }\end{array}$ & $\begin{array}{l}\text { Data acquisition, analysis } \\
\text { and interpretation; } \\
\text { writing and critically }\end{array}$ & $\begin{array}{l}\text { Supported by an Early } \\
\text { Investigator Award } \\
\text { from the Department }\end{array}$ \\
\hline $\begin{array}{l}\text { Edward } \\
\text { Crosby, } \\
\text { MD }\end{array}$ & $\begin{array}{l}\text { Data acquisition, analysis } \\
\text { and interpretation; } \\
\text { writing and critically } \\
\text { revising article; final } \\
\text { approval of version to be } \\
\text { published. }\end{array}$ & None & & $\begin{array}{l}\text { revising article; final } \\
\text { approval of version to be } \\
\text { published. }\end{array}$ & $\begin{array}{l}\text { of Anesthesiology and } \\
\text { Pain Medicine, } \\
\text { University of Toronto } \\
\text { and Toronto General } \\
\text { Hospital }\end{array}$ \\
\hline $\begin{array}{l}\text { Andrew } \\
\text { Downey, } \\
\text { MBBS }\end{array}$ & $\begin{array}{l}\text { Data acquisition, analysis } \\
\text { and interpretation; } \\
\text { critically revising article; } \\
\text { final approval of version } \\
\text { to be published. }\end{array}$ & None & $\begin{array}{l}\text { Roanne } \\
\text { Preston, } \\
\text { MD }\end{array}$ & $\begin{array}{l}\text { Data acquisition, analysis } \\
\text { and interpretation; } \\
\text { critically revising article; } \\
\text { final approval of version } \\
\text { to be published. }\end{array}$ & None \\
\hline \multirow[t]{2}{*}{$\begin{array}{l}\text { Orlando R. } \\
\text { Hung, MD }\end{array}$} & \multirow[t]{2}{*}{$\begin{array}{l}\text { Data acquisition, analysis } \\
\text { and interpretation; } \\
\text { critically revising article; } \\
\text { final approval of version } \\
\text { to be published. }\end{array}$} & \multirow{2}{*}{$\begin{array}{l}\text { Holds a US patent of a } \\
\text { Light-guided Tracheal } \\
\text { Intubation Device. } \\
\text { Co-authored a textbook: } \\
\text { Management of the } \\
\text { Difficult and Failed } \\
\text { Airway. }\end{array}$} & $\begin{array}{l}\text { Nick Sowers, } \\
\text { MD }\end{array}$ & $\begin{array}{l}\text { Data acquisition, analysis } \\
\text { and interpretation; } \\
\text { critically revising article; } \\
\text { final approval of version } \\
\text { to be published. }\end{array}$ & None \\
\hline & & & $\begin{array}{l}\text { Kathryn } \\
\text { Sparrow, } \\
\text { MD, }\end{array}$ & $\begin{array}{l}\text { Data acquisition, analysis } \\
\text { and interpretation; } \\
\text { writing and critically }\end{array}$ & $\begin{array}{l}\text { Received one prior } \\
\text { honorarium for } \\
\text { attending an expert }\end{array}$ \\
\hline $\begin{array}{l}\text { Philip M. } \\
\text { Jones, } \\
\text { MD, MSc }\end{array}$ & $\begin{array}{l}\text { Data acquisition, analysis } \\
\text { and interpretation; } \\
\text { critically revising article; } \\
\text { final approval of version } \\
\text { to be published. }\end{array}$ & $\begin{array}{l}\text { No industry conflicts to } \\
\text { declare. } \\
\text { Dr Jones is Deputy } \\
\text { Editor-in-Chief of the } \\
\text { Canadian Journal of } \\
\text { Anesthesia. }\end{array}$ & MScHQ & $\begin{array}{l}\text { revising article; final } \\
\text { approval of version to be } \\
\text { published. }\end{array}$ & $\begin{array}{l}\text { input forum from } \\
\text { Merck Canada Inc. As } \\
\text { an instructor and } \\
\text { course faculty } \\
\text { member, she has } \\
\text { received honoraria }\end{array}$ \\
\hline \multirow[t]{3}{*}{$\begin{array}{l}\text { George } \\
\text { Kovacs, } \\
\text { MD, } \\
\text { MHPE }\end{array}$} & \multirow[t]{3}{*}{$\begin{array}{l}\text { Data acquisition, analysis } \\
\text { and interpretation; } \\
\text { critically revising article; } \\
\text { final approval of version } \\
\text { to be published. }\end{array}$} & $\begin{array}{l}\text { Work supported by the } \\
\text { Department of } \\
\text { Emergency Medicine, } \\
\text { Dalhousie University. } \\
\text { Course co-director of } \\
\text { Airway Interventions } \\
\text { and Management in }\end{array}$ & & & $\begin{array}{l}\text { from Airway } \\
\text { Interventions and } \\
\text { Management in } \\
\text { Emergencies (AIME), } \\
\text { The Difficult Airway } \\
\text { Course, and Heart and } \\
\text { Stroke Foundation of } \\
\text { Canada. }\end{array}$ \\
\hline & & $\begin{array}{l}\text { Emergencies (AIME) } \\
\text { course and partner in } \\
\text { parent company } \\
\text { AIME Training Inc. } \\
\text { Recipient of } \\
\text { equipment as loan or } \\
\text { donation from }\end{array}$ & $\begin{array}{l}\text { Timothy P. } \\
\text { Turkstra, } \\
\text { MD, } \\
\text { MEng }\end{array}$ & $\begin{array}{l}\text { Data acquisition, analysis } \\
\text { and interpretation; } \\
\text { writing and critically } \\
\text { revising article; final } \\
\text { approval of version to be } \\
\text { published. }\end{array}$ & None \\
\hline & & $\begin{array}{l}\text { Verathon, Ambu, Karl } \\
\text { Storz and Covidien. }\end{array}$ & $\begin{array}{l}\text { David T. } \\
\text { Wong, } \\
\text { MD }\end{array}$ & $\begin{array}{l}\text { Data acquisition, analysis } \\
\text { and interpretation; } \\
\text { critically revising article; }\end{array}$ & $\begin{array}{l}\text { Board of Directors, } \\
\text { Society for Airway } \\
\text { Management }\end{array}$ \\
\hline
\end{tabular}

Appendix continued 


\section{References}

1. Cook T, Woodall N, Frerk C. 4th National Audit Project of the Royal College of Anaesthetists and the Difficult Airway Society. Major complications of airway management in the United Kingdom. London: The Royal College of Anaesthetists; 2011.

2. Joffe AM, Aziz MF, Posner KL, Duggan LV, Mincer SL, Domino $K B$. Management of difficult tracheal intubation: a closed claims analysis. Anesthesiology 2019; 131: 818-29.

3. Crosby ET, Duggan LV, Finestone PJ, Liu R, De Gorter R, Calder LA. Anesthesiology airway-related medicolegal cases from the Canadian Medical Protection Association. Can J Anesth 2021; 68: 183-95.

4. Lewis SR, Butler AR, Parker J, Cook TM, Smith AF. Videolaryngoscopy versus direct laryngoscopy for adult patients requiring tracheal intubation. Cochrane Database Syst Rev 2016; DOI: https://doi.org/10.1002/14651858.CD011136. pub2.

5. Law JA, Duggan LV, Asselin M, et al. Canadian Airway Focus Group consensus-based recommendations for management of the difficult airway: part 1. Difficult airway management encountered in an unconscious patient. Can J Anesth 2021; DOI: https://doi.org/10.1007/s12630-021-02007-0.

6. Frerk C, Mitchell VS, McNarry AF, et al. Difficult Airway Society 2015 guidelines for management of unanticipated difficult intubation in adults. Br J Anaesth 2015; 115: 827-48.

7. Higgs A, McGrath BA, Goddard C, et al. Guidelines for the management of tracheal intubation in critically ill adults. Br J Anaesth 2018; 120: 323-52.

8. Piepho T, Cavus E, Noppens $R$, et al. S1 guidelines on airway management: guideline of the German Society of Anesthesiology and Intensive Care Medicine. Anaesthesist 2015; 64(Suppl 1): 27-40.

9. Myatra SN, Shah A, Kundra P, et al. All India Difficult Airway Association 2016 guidelines for the management of unanticipated difficult tracheal intubation in adults. Indian $\mathbf{J}$ Anaesth 2016; 60: 885-98.

10. Cook TM. Strategies for the prevention of airway complications - a narrative review. Anaesthesia 2018; 73: 93-111.

11. Detsky ME, Jivraj N, Adhikari NK, et al. Will this patient be difficult to intubate?: the Rational Clinical Examination Systematic Review. JAMA 2019; 321: 493-503.

12. Sheff SR, May MC, Carlisle SE, Kallies KJ, Mathiason MA, Kothari SN. Predictors of a difficult intubation in the bariatric patient: does preoperative body mass index matter? Surg Obes Relat Dis 2013; 9: 344-9.

13. Lundstrom $L H$. Detection of risk factors for difficult tracheal intubation. Dan Med J 2012; 59: B4431.

14. Kim WH, Ahn HJ, Lee CJ, et al. Neck circumference to thyromental distance ratio: a new predictor of difficult intubation in obese patients. Br J Anaesth 2011; 106: 743-8.

15. De Cassai A, Papaccio F, Betteto G, Schiavolin C, Iacobone M, Carron $M$. Prediction of difficult tracheal intubations in thyroid surgery. Predictive value of neck circumference to thyromental distance ratio. PLoS One 2019; DOI: https://doi.org/10.1371/ journal.pone.0212976.

16. Roth D, Pace NL, Lee A, et al. Bedside tests for predicting difficult airways: an abridged Cochrane diagnostic test accuracy systematic review. Anaesthesia 2019; 74: 915-28.

17. Pandit JJ, Heidegger T. Putting the 'point' back into the ritual: a binary approach to difficult airway prediction. Anaesthesia 2017; 72: 283-8.

18. Croskerry P. Cognitive forcing strategies in clinical decisionmaking. Ann Emerg Med 2003; 41: 110-20.
19. Rosenblatt W, Ianus AI, Sukhupragarn W, Fickenscher A, Sasaki $C$. Preoperative endoscopic airway examination (PEAE) provides superior airway information and may reduce the use of unnecessary awake intubation. Anesth Analg 2011; 112: 602-7.

20. El-Boghdadly K, Onwochei DN, Millhoff B, Ahmad I. The effect of virtual endoscopy on diagnostic accuracy and airway management strategies in patients with head and neck pathology: a prospective cohort study. Can J Anesth 2017; 64: 1101-10.

21. Sakles JC, Pacheco GS, Kovacs G, Mosier JM. The difficult airway refocused. Br J Anaesth 2020; 125: e18-21.

22. Kristensen MS, Teoh WH. Ultrasound identification of the cricothyroid membrane: the new standard in preparing for frontof-neck airway access. Br J Anaesth 2021; 126: 22-7.

23. Kristensen MS, Teoh WH, Rudolph SS. Ultrasonographic identification of the cricothyroid membrane: best evidence, techniques, and clinical impact. Br J Anaesth 2016; 117(Suppl 1): i39-48.

24. Bowness J, Teoh WH, Kristensen MS, et al. A marking of the cricothyroid membrane with extended neck returns to correct position after neck manipulation and repositioning. Acta Anaesthesiol Scand 2020; 64: 1422-5.

25. Moon TS, Fox PE, Somasundaram A, et al. The influence of morbid obesity on difficult intubation and difficult mask ventilation. J Anesth 2019; 33: 96-102.

26. Hanouz JL, Bonnet $V$, Buleon $C$, et al. Comparison of the Mallampati classification in sitting and supine position to predict difficult tracheal intubation: a prospective observational cohort study. Anesth Analg 2018; 126: 161-9.

27. Mahmoodpoor A, Soleimanpour H, Golzari SE, et al. Determination of the diagnostic value of the Modified Mallampati score, Upper Lip Bite Test and Facial Angle in predicting difficult intubation: a prospective descriptive study. J Clin Anesth 2017; 37: 99-102.

28. Riad W, Vaez $M N$, Raveendran $R$, et al. Neck circumference as a predictor of difficult intubation and difficult mask ventilation in morbidly obese patients: a prospective observational study. Eur J Anaesthesiol 2016; 33: 244-9.

29. Healy DW, LaHart EJ, Peoples EE, Jewell ES, Bettendorf RJ Jr, Ramachandran $S K$. A comparison of the Mallampati evaluation in neutral or extended cervical spine positions: a retrospective observational study of $>80000$ patients. Br J Anaesth 2016; 116: 690-8.

30. Khan ZH, Eskandari S, Yekaninejad MS. A comparison of the Mallampati test in supine and upright positions with and without phonation in predicting difficult laryngoscopy and intubation: a prospective study. J Anaesthesiol Clin Pharmacol 2015; 31: 207-11.

31. Heinrich S, Birkholz T, Irouschek A, Ackermann A, Schmidt J. Incidences and predictors of difficult laryngoscopy in adult patients undergoing general anesthesia : a single-center analysis of 102,305 cases. J Anesth 2013; 27: 815-21.

32. Ono $K$, Goto T, Nakai D, Ueki S, Takenaka S, Moriya T. Incidence and predictors of difficult nasotracheal intubation with airway scope. J Anesth 2014; 28: 650-4.

33. Aziz MF, Healy D, Kheterpal S, Fu RF, Dillman D, Brambrink $A M$. Routine clinical practice effectiveness of the Glidescope in difficult airway management: an analysis of 2,004 Glidescope intubations, complications, and failures from two institutions. Anesthesiology 2011; 114: 34-41.

34. Diaz-Gomez, JL, Satyapriya A, Satyapriya SV, et al. Standard clinical risk factors for difficult laryngoscopy are not independent predictors of intubation success with the GlideScope. J Clin Anesth 2011; 23: 603-10. 
35. Tremblay $M H$, Williams $S$, Robitaille A, Drolet $P$. Poor visualization during direct laryngoscopy and high upper lip bite test score are predictors of difficult intubation with the GlideScope videolaryngoscope. Anesth Analg 2008; 106: 1495-500.

36. Aziz MF, Bayman EO, Van Tienderen MM, Todd MM; StAGE Investigator Group; Brambrink AM. Predictors of difficult videolaryngoscopy with GlideScope(R) or C-MAC(R) with D-blade: secondary analysis from a large comparative videolaryngoscopy trial. Br J Anaesth 2016; 117: 118-23.

37. Nowakowski M, Williams $S$, Gallant J, Ruel M, Robitaille A. Predictors of difficult intubation with the Bonfils rigid fiberscope. Anesth Analg 2016; 122: 1901-6.

38. Toure T, Williams SR, Kerouch M, Ruel M. Patient factors associated with difficult flexible bronchoscopic intubation under general anesthesia: a prospective observational study. Can J Anesth 2020; 67: 706-14.

39. Shah PN, Sundaram $V$. Incidence and predictors of difficult mask ventilation and intubation. J Anaesthesiol Clin Pharmacol 2012; 28: 451-5.

40. Cattano D, Killoran PV, Cai C, Katsiampoura AD, Corso RM, Hagberg $C A$. Difficult mask ventilation in general surgical population: observation of risk factors and predictors. F1000Res 2014; DOI: https://doi.org/10.12688/f1000research.5131.1.

41. Leoni A, Arlati S, Ghisi D, et al. Difficult mask ventilation in obese patients: analysis of predictive factors. Minerva Anestesiol 2014; 80: 149-57.

42. Cattano D, Katsiampoura A, Corso RM, Killoran PV, Cai C, Hagberg $C A$. Predictive factors for difficult mask ventilation in the obese surgical population. F1000Res 2014; DOI: https://doi. org/10.12688/f1000research.5471.1.

43. Kheterpal S, Martin L, Shanks AM, Tremper KK. Prediction and outcomes of impossible mask ventilation: a review of 50,000 anesthetics. Anesthesiology 2009; 110: 891-7.

44. Kheterpal S, Healy D, Aziz MF, et al. Incidence, predictors, and outcome of difficult mask ventilation combined with difficult laryngoscopy: a report from the multicenter perioperative outcomes group. Anesthesiology 2013; 119: 1360-9.

45. Kheterpal S, Han R, Tremper KK, et al. Incidence and predictors of difficult and impossible mask ventilation. Anesthesiology 2006; 105: 885-91.

46. Langeron $O$, Masso E, Huraux $C$, et al. Prediction of difficult mask ventilation. Anesthesiology 2000; 92: 1229-36.

47. Gautam P, Gaul TK, Luthra N. Prediction of difficult mask ventilation. Eur J Anaesthesiol 2005; 22: 638-40.

48. Yildiz TS, Solak M, Toker K. The incidence and risk factors of difficult mask ventilation. J Anesth 2005; 19: 7-11.

49. Ramachandran SK, Mathis MR, Tremper KK, Shanks AM, Kheterpal S. Predictors and clinical outcomes from failed Laryngeal Mask Airway Unique ${ }^{\mathrm{TM}}$ : a study of 15,795 patients. Anesthesiology 2012; 116: 1217-26.

50. Katsiampoura AD, Killoran PV, Corso RM, Cai C, Hagberg CA, Cattano D. Laryngeal mask placement in a teaching institution: analysis of difficult placements. F1000Res 2015; 4: 102.

51. Vannucci A, Rossi IT, Prifti K, et al. Modifiable and nonmodifiable factors associated with perioperative failure of extraglottic airway devices. Anesth Analg 2018; 126: 1959-67.

52. Di Filippo A, Adembri C, Paparella L, et al. Risk factors for difficult Laryngeal Mask Airway LMA-Supreme ${ }^{\mathrm{TM}}$ (LMAS) placement in adults: a multicentric prospective observational study in an Italian population. Minerva Anestesiol 2021; DOI: https://doi.org/10.23736/S0375-9393.20.15001-6.

53. Mosier JM, Joshi R, Hypes C, Pacheco G, Valenzuela T, Sakles $J C$. The physiologically difficult airway. West J Emerg Med 2015; 16: 1109-17.
54. Kornas RL, Owyang CG, Sakles JC, Foley LJ, Mosier JM; Society for Airway Management's Special Projects Committee. Evaluation and management of the physiologically difficult airway: consensus recommendations from Society for Airway Management. Anesth Analg 2021; 132: 395-405.

55. Cook TM, MacDougall-Davis SR. Complications and failure of airway management. Br J Anaesth 2012; 109(Suppl 1): i68-85.

56. Williamson JA, Webb RK, Szekely S, Gillies ER, Dreosti AV. The Australian Incident Monitoring Study. Difficult intubation: an analysis of 2000 incident reports. Anaesth Intensive Care 1993; 21: 602-7.

57. Norskov AK, Rosenstock CV, Wetterslev J, Astrup G, Afshari A, Lundstrom LH. Diagnostic accuracy of anaesthesiologists' prediction of difficult airway management in daily clinical practice: a cohort study of 188064 patients registered in the Danish Anaesthesia Database. Anaesthesia 2015; 70: 272-81.

58. Mosier JM. Physiologically difficult airway in critically ill patients: winning the race between haemoglobin desaturation and tracheal intubation. Br J Anaesth 2020; 125: e1-4.

59. Law JA, Morris IR, Brousseau PA, de la Ronde S, Milne AD. The incidence, success rate, and complications of awake tracheal intubation in 1,554 patients over 12 years: an historical cohort study. Can J Anesth 2015; 62: 736-44.

60. Joseph TT, Gal JS, DeMaria S Jr, Lin HM, Levine AI, Hyman $J B$. A retrospective study of success, failure, and time needed to perform awake intubation. Anesthesiology 2016; 125: 105-14.

61. El-Boghdadly K, Onwochei DN, Cuddihy J, Ahmad I. A prospective cohort study of awake fibreoptic intubation practice at a tertiary centre. Anaesthesia 2017; 72: 694-703.

62. Knudsen K, Nilsson U, Hogman M, Poder $U$. Awake intubation creates feelings of being in a vulnerable situation but cared for in safe hands: a qualitative study. BMC Anesthesiol 2016; DOI: https://doi.org/10.1186/s12871-016-0240-z.

63. Ahmad I, El-Boghdadly K, Bhagrath R, et al. Difficult Airway Society guidelines for awake tracheal intubation (ATI) in adults. Anaesthesia 2020; 75: 509-28.

64. Martin KM, Larsen PD, Segal $R$, Marsland $C P$. Effective nonanatomical endoscopy training produces clinical airway endoscopy proficiency. Anesth Analg 2004; 99: 938-44.

65. Johnston KD, Rai MR. Conscious sedation for awake fibreoptic intubation: a review of the literature. Can J Anesth 2013; 60: 584-99.

66. Zhou LJ, Fang XZ, Gao J, Zhangm Y, Tao LJ. Safety and efficacy of dexmedetomidine as a sedative agent for performing awake intubation: a meta-analysis. Am J Ther 2016; 23: e1788800 .

67. Heidegger T, Schnider TW. "Awake" or "sedated": safe flexible bronchoscopic intubation of the difficult airway. Anesth Analg 2017; 124: 996-7.

68. McGuire G, el-Beheiry H. Complete upper airway obstruction during awake fibreoptic intubation in patients with unstable cervical spine fractures. Can J Anesth 1999; 46: 176-8.

69. He XY, Cao JP, He $Q$, Shi XY. Dexmedetomidine for the management of awake fibreoptic intubation. Cochrane Database Syst Rev 2014; DOI: https://doi.org/10.1002/14651858. CD009798.pub2.

70. Rosenstock CV, Thogersen B, Afshari A, Christensen $A L$, Eriksen $C$, Gatke $M R$. Awake fiberoptic or awake video laryngoscopic tracheal intubation in patients with anticipated difficult airway management: a randomized clinical trial. Anesthesiology 2012; 116: 1210-6.

71. Mendonca C, Mesbah A, Velayudhan A, Danha R. A randomised clinical trial comparing the flexible fibrescope and the Pentax Airway Scope (AWS)((R)) for awake oral tracheal intubation. Anaesthesia 2016; 71: 908-14. 
72. Kramer A, Muller D, Pfortner $R$, Mohr C, Groeben $H$. Fibreoptic vs videolaryngoscopic (C-MAC((R)) D-BLADE) nasal awake intubation under local anaesthesia. Anaesthesia 2015; 70: 400-6.

73. Alhomary $M$, Ramadan E, Curran E, Walsh SR. Videolaryngoscopy vs. fibreoptic bronchoscopy for awake tracheal intubation: a systematic review and meta-analysis. Anaesthesia 2018; 73: 1151-61.

74. Jiang J, Ma DX, Li B, Wu AS, Xue FS. Videolaryngoscopy versus fiberoptic bronchoscope for awake intubation - a systematic review and meta-analysis of randomized controlled trials. Ther Clin Risk Manag 2018; 14: 1955-63.

75. Aziz MF, Kristensen MS. From variance to guidance for awake tracheal intubation. Anaesthesia 2020; 75: 442-6.

76. Wilson WM, Smith AF. The emerging role of awake videolaryngoscopy in airway management. Anaesthesia 2018; 73: 1058-61.

77. Lim WY, Wong P. Awake supraglottic airway guided flexible bronchoscopic intubation in patients with anticipated difficult airways: a case series and narrative review. Korean J Anesthesiol 2019; 72: 548-57.

78. Jagannathan N, Kozlowski RJ, Sohn LE, et al. A clinical evaluation of the intubating laryngeal airway as a conduit for tracheal intubation in children. Anesth Analg 2011; 112: 176-82.

79. Jagannathan $N$, Truong $C T$. A simple method to deliver pharyngeal anesthesia in syndromic infants prior to awake insertion of the intubating laryngeal airway. Can J Anesth 2010; 57: 1138-9.

80. Johnson CM, Sims C. Awake fibreoptic intubation via a laryngeal mask in an infant with Goldenhar's syndrome. Anaesth Intensive Care 1994; 22: 194-7.

81. Peterson GN, Domino KB, Caplan RA, Posner KL, Lee LA, Cheney $F W$. Management of the difficult airway: a closed claims analysis. Anesthesiology 2005; 103: 33-9.

82. Ho AM, Chung DC, To EW, Karmakar MK. Total airway obstruction during local anesthesia in a non-sedated patient with a compromised airway. Can J Anesth 2004; 51: 838-41.

83. Shaw IC, Welchew EA, Harrison BJ, Michael S. Complete airway obstruction during awake fibreoptic intubation. Anaesthesia 1997; 52: 582-5.

84. Mason RA, Fielder CP. The obstructed airway in head and neck surgery. Anaesthesia 1999; 54: 625-8.

85. Liistro G, Stanescu DC, Veriter C, Rodenstein DO, D'Odemont $J P$. Upper airway anesthesia induces airflow limitation in awake humans. Am Rev Respir Dis 1992; 146: 581-5.

86. Malpas $G$, Hung $O$, Gilchrist A, et al. The use of extracorporeal membrane oxygenation in the anticipated difficult airway: a case report and systematic review. Can J Anesth 2018; 65: 685-97.

87. Fung R, Stellios J, Bannon PG, Ananda A, Forrest P. Elective use of veno-venous extracorporeal membrane oxygenation and high-flow nasal oxygen for resection of subtotal malignant distal airway obstruction. Anaesth Intensive Care 2017; 45: 88-91.

88. Collar RM, Taylor JC, Hogikyan ND, Tutuo N, Ohye RG, Green $G E$. Awake extracorporeal membrane oxygenation for management of critical distal tracheal obstruction. Otolaryngol Head Neck Surg 2010; 142: 618-20.

89. Kim S, Khromava M, Zerillo J, Silvay G, Levine AI. Anesthetic management of a patient with tracheal dehiscence post-tracheal resection surgery. Semin Cardiothorac Vasc Anesth 2017; 21: 360-3.

90. Karim AS, Son AY, Suen R, et al. Pre-intubation veno-venous extracorporeal membrane oxygenation in patients at risk for respiratory decompensation. J Extra Corpor Technol 2020; 52: 52-7.

91. Gudivada KK, Jonnavithula N, Pasupuleti SL, Apparasu CP, Ayya SS, Ramachandran G. Comparison of ease of intubation in sniffing position and further neck flexion. $\mathrm{J}$ Anaesthesiol Clin Pharmacol 2017; 33: 342-7.

92. El-Orbany $M$, Woehlck $H$, Salem MR. Head and neck position for direct laryngoscopy. Anesth Analg 2011; 113: 103-9.

93. El-Orbany MI, Getachew YB, Joseph NJ, Salem MR, Friedman $M$. Head elevation improves laryngeal exposure with direct laryngoscopy. J Clin Anesth 2015; 27: 153-8.

94. Adnet F, Baillard C, Borron SW, et al. Randomized study comparing the "sniffing position" with simple head extension for laryngoscopic view in elective surgery patients. Anesthesiology 2001; 95: 836-41.

95. Greenland KB, Edwards MJ, Hutton NJ, Challis VJ, Irwin MG, Sleigh JW. Changes in airway configuration with different head and neck positions using magnetic resonance imaging of normal airways: a new concept with possible clinical applications. Br J Anaesth 2010; 105: 683-90.

96. Lebowitz PW, Shay H, Straker T, Rubin D, Bodner S. Shoulder and head elevation improves laryngoscopic view for tracheal intubation in nonobese as well as obese individuals. J Clin Anesth 2012; 24: 104-8.

97. Lee JH, Jung HC, Shim JH, Lee C. Comparison of the rate of successful endotracheal intubation between the "sniffing" and "ramped" positions in patients with an expected difficult intubation: a prospective randomized study. Korean J Anesthesiol 2015; 68: 116-21.

98. Collins JS, Lemmens HJ, Brodsky JB, Brock-Utne JG, Levitan $R M$. Laryngoscopy and morbid obesity: a comparison of the "sniff" and "ramped" positions. Obes Surg 2004; 14: 1171-5.

99. Reddy RM, Adke M, Patil P, Kosheleva I, Ridley S; Anaesthetic Department at Glan Clwyd Hospital. Comparison of glottic views and intubation times in the supine and 25 degree back-up positions. BMC Anesthesiol 2016; DOI: https://doi.org/10.1186/ s12871-016-0280-4.

100. Murphy DL, Rea TD, McCoy AM, et al. Inclined position is associated with improved first pass success and laryngoscopic view in prehospital endotracheal intubations. Am J Emerg Med 2019; 37: 937-41.

101. Khandelwal N, Khorsand S, Mitchell SH, Joffe AM. Headelevated patient positioning decreases complications of emergent tracheal intubation in the ward and intensive care unit. Anesth Analg 2016; 122: 1101-7.

102. Turner JS, Ellender TJ, Okonkwo ER, et al. Feasibility of upright patient positioning and intubation success rates at two academic EDs. Am J Emerg Med 2017; 35: 986-92.

103. Semler $M W$, Janz DR, Russell DW, et al. A multicenter, randomized trial of ramped position vs sniffing position during endotracheal intubation of critically ill adults. Chest 2017; 152: 712-22.

104. Lee BJ, Kang JM, Kim DO. Laryngeal exposure during laryngoscopy is better in the 25 degrees back-up position than in the supine position. Br J Anaesth 2007; 99: 581-6.

105. Singleton BN, Morris FK, Yet B, Buggy DJ, Perkins ZB. Effectiveness of intubation devices in patients with cervical spine immobilisation: a systematic review and network metaanalysis. Br J Anaesth 2021; DOI: https://doi.org/10.1016/j.bja. 2020.12.041.

106. Isono S, Tanaka A, Ishikawa T, Tagaito $Y$, Nishino T. Sniffing position improves pharyngeal airway patency in anesthetized patients with obstructive sleep apnea. Anesthesiology 2005; 103: 489-94.

107. Mitterlechner T, Paal P, Kuehnelt-Leddhin L, et al. Head position angles to open the upper airway differ less with the head positioned on a support. Am J Emerg Med 2013; 31: 80-5.

108. Intersurgical. User guide: i-gel ${ }^{\circledR}$ single use supraglottic airway. Available from URL: https://www.intersurgical.com/products/ 
airway-management/i-gel-supraglottic-airway\#downloads (accessed March 2021).

109. The Laryngeal Mask Company Limited. Instructions for use LMA Classic Excel ${ }^{\mathrm{TM}}$. Available from URL: http://www.lmacoifu.com/sites/default/files/node/1898/ifu/revision/2921/ paa2100001c.pdf (accessed March 2021).

110. Kim MS, Park JH, Lee KY, et al. Influence of head and neck position on the performance of supraglottic airway devices: a systematic review and meta-analysis. PLoS One 2019; DOI: https://doi.org/10.1371/journal.pone.0216673.

111. Dixit A, Ramaswamy KK, Perera S, Sukumar V, Frerk C. Impact of change in head and neck position on ultrasound localisation of the cricothyroid membrane: an observational study. Anaesthesia 2019; 74: 29-32.

112. Pandit JJ, Duncan T, Robbins PA. Total oxygen uptake with two maximal breathing techniques and the tidal volume breathing technique: a physiologic study of preoxygenation. Anesthesiology 2003; 99: 841-6.

113. Rajan S, Mohan P, Paul J, Cherian A. Comparison of margin of safety following two different techniques of preoxygenation. J Anaesthesiol Clin Pharmacol 2015; 31: 165-8.

114. Tanoubi I, Drolet P, Donati F. Optimizing preoxygenation in adults. Can J Anesth 2009; 56: 449-66.

115. Driver BE, Prekker ME, Kornas RL, Cales EK, Reardon RF. Flush rate oxygen for emergency airway preoxygenation. Ann Emerg Med 2017; 69: 1-6.

116. Boyce JR, Ness T, Castroman P, Gleysteen JJ. A preliminary study of the optimal anesthesia positioning for the morbidly obese patient. Obes Surg 2003; 13: 4-9.

117. Dixon BJ, Dixon JB, Carden JR, et al. Preoxygenation is more effective in the 25 degrees head-up position than in the supine position in severely obese patients: a randomized controlled study. Anesthesiology 2005; 102: 1110-5.

118. Altermatt FR, Munoz HR, Delfino AE, Cortinez LI. Preoxygenation in the obese patient: effects of position on tolerance to apnoea. Br J Anaesth 2005; 95: 706-9.

119. Ramkumar V, Umesh G, Philip FA. Preoxygenation with 20 head-up tilt provides longer duration of non-hypoxic apnea than conventional preoxygenation in non-obese healthy adults. J Anesth 2011; 25: 189-94.

120. Lane S, Saunders D, Schofield A, Padmanabhan R, Hildreth A, Laws $D$. A prospective, randomised controlled trial comparing the efficacy of pre-oxygenation in the 20 degrees head-up vs supine position. Anaesthesia 2005; 60: 1064-7.

121. Benedik PS, Baun MM, Keus L, et al. Effects of body position on resting lung volume in overweight and mildly to moderately obese subjects. Respir Care 2009; 54: 334-9.

122. Hignett $R$, Fernando $R$, McGlennan A, et al. A randomized crossover study to determine the effect of a 30 head-up versus a supine position on the functional residual capacity of term parturients. Anesth Analg 2011; 113: 1098-102.

123. Couture EJ, Provencher S, Somma J, Lellouche F, Marceau S, Bussieres JS. Effect of position and positive pressure ventilation on functional residual capacity in morbidly obese patients: a randomized trial. Can J Anesth 2018; 65: 522-8.

124. Smith SJ, Harten JM, Jack E, Carter R, Kinsella J. Preoxygenation in healthy volunteers: a comparison of the supine and 45 seated positions. Anaesthesia 2010; 65: 980-3.

125. Mosier JM, Hypes CD, Sakles JC. Understanding preoxygenation and apneic oxygenation during intubation in the critically ill. Intensive Care Med 2017; 43: 226-8.

126. Pourmand A, Robinson C, Dorwart K, O'Connell F. Preoxygenation: implications in emergency airway management. Am J Emerg Med 2017; 35: 1177-83.
127. Nimmagadda U, Salem MR, Crystal GJ. Preoxygenation: physiologic basis, benefits, and potential risks. Anesth Analg 2017; 124: 507-17.

128. Fong KM, Au SY, $\mathrm{Ng} G W$. Preoxygenation before intubation in adult patients with acute hypoxemic respiratory failure: a network meta-analysis of randomized trials. Crit Care 2019; DOI: https://doi.org/10.1186/s13054-019-2596-1.

129. Jaber S, Monnin M, Girard M, et al. Apnoeic oxygenation via high-flow nasal cannula oxygen combined with non-invasive ventilation preoxygenation for intubation in hypoxaemic patients in the intensive care unit: the single-centre, blinded, randomised controlled OPTINIV trial. Intensive Care Med 2016; 42: 1877-87.

130. Hardman JG, Wills $J S$. The development of hypoxaemia during apnoea in children: a computational modelling investigation. $\mathrm{Br}$ J Anaesth 2006; 97: 564-70.

131. Weingart SD, Levitan RM. Preoxygenation and prevention of desaturation during emergency airway management. Ann Emerg Med 2012; 59: 165-75.e1.

132. Wong DT, Yee AJ, Leong SM, Chung F. The effectiveness of apneic oxygenation during tracheal intubation in various clinical settings: a narrative review. Can J Anesth 2017; 64: 416-27.

133. Hermez LA, Spence CJ, Payton MJ, Nouraei SA, Patel A, Barnes $T H$. A physiological study to determine the mechanism of carbon dioxide clearance during apnoea when using transnasal humidified rapid insufflation ventilatory exchange (THRIVE). Anaesthesia 2019; 74: 441-9.

134. Lyons $C$, Callaghan M. Apnoeic oxygenation with high-flow nasal oxygen for laryngeal surgery: a case series. Anaesthesia 2017; 72: 1379-87.

135. Spence EA, Rajaleelan W, Wong J, Chung F, Wong DT. The effectiveness of high-flow nasal oxygen during the intraoperative period: a systematic review and meta-analysis. Anesth Analg 2020; 131: 1102-10.

136. Humphreys S, Lee-Archer P, Reyne G, Long D, Williams $T$, Schibler A. Transnasal humidified rapid-insufflation ventilatory exchange (THRIVE) in children: a randomized controlled trial. Br J Anaesth 2017; 118: 232-8.

137. Riva T, Pedersen TH, Seiler S, et al. Transnasal humidified rapid insufflation ventilatory exchange for oxygenation of children during apnoea: a prospective randomised controlled trial. Br J Anaesth 2018; 120: 592-9.

138. Wong DT, Dallaire A, Singh KP, et al. High-flow nasal oxygen improves safe apnea time in morbidly obese patients undergoing general anesthesia: a randomized controlled trial. Anesth Analg 2019; 129: 1130-6.

139. Rajan S, Joseph N, Tosh P, Kadapamannil D, Paul J, Kumar L. Effectiveness of transnasal humidified rapid-insufflation ventilatory exchange versus traditional preoxygenation followed by apnoeic oxygenation in delaying desaturation during apnoea: a preliminary study. Indian J Anaesth 2018; 62: 202-7.

140. Ramachandran SK, Cosnowski A, Shanks A, Turner CR. Apneic oxygenation during prolonged laryngoscopy in obese patients: a randomized, controlled trial of nasal oxygen administration. J Clin Anesth 2010; 22: 164-8.

141. Lodenius A, Piehl J, Ostlund A, Ullman J, Jonsson Fagerlund $M$. Transnasal humidified rapid-insufflation ventilatory exchange (THRIVE) vs. facemask breathing pre-oxygenation for rapid sequence induction in adults: a prospective randomised non-blinded clinical trial. Anaesthesia 2018; 73: 564-71.

142. Tan E, Loubani O, Kureshi N, Green RS. Does apneic oxygenation prevent desaturation during emergency airway management? A systematic review and meta-analysis. Can J Anesth 2018; 65: 936-49. 
143. Miguel-Montanes R, Hajage D, Messika J, et al. Use of highflow nasal cannula oxygen therapy to prevent desaturation during tracheal intubation of intensive care patients with mildto-moderate hypoxemia. Crit Care Med 2015; 43: 574-83.

144. Sakles JC, Mosier JM, Patanwala AE, Dicken JM. Apneic oxygenation is associated with a reduction in the incidence of hypoxemia during the RSI of patients with intracranial hemorrhage in the emergency department. Intern Emerg Med 2016; 11: 983-92.

145. Vourc'h M, Asfar P, Volteau $C$, et al. High-flow nasal cannula oxygen during endotracheal intubation in hypoxemic patients: a randomized controlled clinical trial. Intensive Care Med 2015; 41: $1538-48$.

146. Semler $M W$, Janz DR, Lentz RJ, et al. Randomized trial of apneic oxygenation during endotracheal intubation of the critically ill. Am J Respir Crit Care Med 2016; 193: 273-80.

147. Sakles JC, Mosier JM, Patanwala AE, Arcaris B, Dicken JM. First pass success without hypoxemia is increased with the use of apneic oxygenation during rapid sequence intubation in the emergency department. Acad Emerg Med 2016; 23: 703-10.

148. Dyett JF, Moser MS, Tobin AE. Prospective observational study of emergency airway management in the critical care environment of a tertiary hospital in Melbourne. Anaesth Intensive Care 2015; 43: 577-86.

149. Simon $M$, Wachs $C$, Braune $S$, de Heer $G$, Frings $D$, Kluge $S$. High-flow nasal cannula versus bag-valve-mask for preoxygenation before intubation in subjects with hypoxemic respiratory failure. Respir Care 2016; 61: 1160-7.

150. Caputo N, Azan B, Domingues $R$, et al. Emergency department use of apneic oxygenation versus usual care during rapid sequence intubation: a randomized controlled trial (The ENDAO Trial). Acad Emerg Med 2017; 24: 1387-94.

151. Patel A, Pearce A. Progress in management of the obstructed airway. Anaesthesia 2011; 66(Suppl 2): 93-100.

152. Maddison KJ, Walsh JH, Shepherd KL, et al. Comparison of collapsibility of the human upper airway during anesthesia and during sleep. Anesth Analg 2020; 130: 1008-17.

153. Hillman DR, Platt PR, Eastwood PR. The upper airway during anaesthesia. Br J Anaesth 2003; 91: 31-9.

154. Hillman DR, Walsh JH, Maddison KJ, et al. Evolution of changes in upper airway collapsibility during slow induction of anesthesia with propofol. Anesthesiology 2009; 111: 63-71.

155. Calder I, Yentis SM. Could 'safe practice' be compromising safe practice? Should anaesthetists have to demonstrate that face mask ventilation is possible before giving a neuromuscular blocker? Anaesthesia 2008; 63: 113-5.

156. Priebe HJ. Should anesthesiologists have to confirm effective facemask ventilation before administering the muscle relaxant? J Anesth 2016; 30: 132-7.

157. Lundstrom LH, Duez CH, Norskov AK, et al. Effects of avoidance or use of neuromuscular blocking agents on outcomes in tracheal intubation: a Cochrane systematic review. Br J Anaesth 2018; 120: 1381-93.

158. Fujiwara A, Komasawa N, Nishihara I, et al. Muscle relaxant effects on insertion efficacy of the laryngeal mask ProSeal((R)) in anesthetized patients: a prospective randomized controlled trial. J Anesth 2015; 29: 580-4.

159. Hattori K, Komasawa N, Miyazaki Y, Kido H, Deguchi S, Minami $T$. Muscle relaxant facilitates i-gel insertion by novice doctors: a prospective randomized controlled trial. J Clin Anesth 2016; 33: 218-22.

160. Joffe AM, Ramaiah $R$, Donahue E, et al. Ventilation by mask before and after the administration of neuromuscular blockade: a pragmatic non-inferiority trial. BMC Anesthesiol 2015; DOI: https://doi.org/10.1186/s12871-015-0111-z.
161. Soltesz S, Alm P, Mathes A, Hellmich M, Hinkelbein J. The effect of neuromuscular blockade on the efficiency of facemask ventilation in patients difficult to facemask ventilate: a prospective trial. Anaesthesia 2017; 72: 1484-90.

162. Sachdeva R, Kannan TR, Mendonca C, Patteril M. Evaluation of changes in tidal volume during mask ventilation following administration of neuromuscular blocking drugs. Anaesthesia 2014; 69: 826-31.

163. Warters RD, Szabo TA, Spinale FG, DeSantis SM, Reves JG. The effect of neuromuscular blockade on mask ventilation. Anaesthesia 2011; 66: 163-7.

164. Goodwin MW, Pandit JJ, Hames K, Popat M, Yentis SM. The effect of neuromuscular blockade on the efficiency of mask ventilation of the lungs. Anaesthesia 2003; 58: 60-3.

165. Amathieu $R$, Combes $X$, Abdi W, et al. An algorithm for difficult airway management, modified for modern optical devices (Airtraq laryngoscope; LMA CTrach ${ }^{\mathrm{TM}}$ ): a 2-year prospective validation in patients for elective abdominal, gynecologic, and thyroid surgery. Anesthesiology 2011; 114: 25-33.

166. Min SH, Im H, Kim BR, Yoon S, Bahk JH, Seo JH. Randomized trial comparing early and late administration of rocuronium before and after checking mask ventilation in patients with normal airways. Anesth Analg 2019; 129: 380-6.

167. Toshniwal G, McKelvey GM, Wang $H$. STOP-Bang and prediction of difficult airway in obese patients. J Clin Anesth 2014; 26: 360-7.

168. Benumof JL, Dagg $R$, Benumof $R$. Critical hemoglobin desaturation will occur before return to an unparalyzed state following $1 \mathrm{mg} / \mathrm{kg}$ intravenous succinylcholine. Anesthesiology 1997; 87: 979-82.

169. Naguib M, Brewer L, LaPierre C, Kopman AF, Johnson KB. The myth of rescue reversal in "can't intubate, can't ventilate" scenarios. Anesth Analg 2016; 123: 82-92.

170. Bisschops MM, Holleman C, Huitink JM. Can sugammadex save a patient in a simulated 'cannot intubate, cannot ventilate' situation? Anaesthesia 2010; 65: 936-41.

171. Kyle BC, Gaylard D, Riley RH. A persistent 'can't intubate, can't oxygenate' crisis despite rocuronium reversal with sugammadex. Anaesth Intensive Care 2012; 40: 344-6.

172. Curtis $R$, Lomax $S$, Patel B. Use of sugammadex in a 'can't intubate, can't ventilate' situation. Br J Anaesth 2012; 108: 612-4.

173. Kovacs $G$, Levitan $R$, Sandeski $R$. Clinical cadavers as a simulation resource for procedural learning. AEM Educ Train 2018; 2: 239-47.

174. Gibbins M, Kelly FE, Cook TM. Airway management equipment and practice: time to optimise institutional, team, and personal preparedness. Br J Anaesth 2020; 125: 221-4.

175. Berlin DA, Gulick RM, Martinez FJ. Severe Covid-19. N Engl J Med 2020; 383: 2451-60.

176. Cook TM. Personal protective equipment during the coronavirus disease (COVID) 2019 pandemic - a narrative review. Anaesthesia 2020; 75: 920-7.

177. Cook TM. Risk to health from COVID-19 for anaesthetists and intensivists - a narrative review. Anaesthesia 2020; 75: 1494-508.

178. Lockhart SL, Duggan LV, Wax RS, Saad S, Grocott HP. Personal protective equipment (PPE) for both anesthesiologists and other airway managers: principles and practice during the COVID-19 pandemic. Can J Anesth 2020; 67: 1005-15.

179. Matava CT, Kovatsis $P G$, Lee $J K$, et al. Pediatric airway management in COVID-19 patients: consensus guidelines from the Society for Pediatric Anesthesia's Pediatric Difficult Intubation Collaborative and the Canadian Pediatric Anesthesia Society. Anesth Analg 2020; 131: 61-73. 
180. Brewster DJ, Chrimes N, Do TB, et al. Consensus statement: Safe Airway Society principles of airway management and tracheal intubation specific to the COVID-19 adult patient group. Med J Aust 2020; 212: 472-81.

181. Cook TM, El-Boghdadly K, McGuire B, McNarry AF, Patel A, Higgs A. Consensus guidelines for managing the airway in patients with COVID-19: guidelines from the Difficult Airway Society, the Association of Anaesthetists the Intensive Care Society, the Faculty of Intensive Care Medicine and the Royal College of Anaesthetists. Anaesthesia 2020; 75: 785-99.

182. Wong $P, \operatorname{Lim} W Y$. Aligning difficult airway guidelines with the anesthetic COVID-19 guidelines to develop a COVID-19 difficult airway strategy: a narrative review. J Anesth 2020; 34: 924-43.

183. Wax RS, Christian MD. Practical recommendations for critical care and anesthesiology teams caring for novel coronavirus (2019-nCoV) patients. Can J Anesth 2020; 67: 568-76.

184. Cook TM, McGuire B, Mushambi M, et al. Airway management guidance for the endemic phase of COVID-19. Anaesthesia 2021; 76: 251-60.

185. Brown J, Gregson FK, Shrimpton A, et al. A quantitative evaluation of aerosol generation during tracheal intubation and extubation. Anaesthesia 2021; 76: 174-81.

186. Kristensen MS, Thomsen JL. Minimising droplet and virus spread during and after tracheal extubation. Br J Anaesth 2020; 125: e197-8.

187. Mercer SJ, Jones CP, Bridge M, Clitheroe E, Morton B, Groom $P$. Systematic review of the anaesthetic management of noniatrogenic acute adult airway trauma. $\mathrm{Br} \mathrm{J}$ Anaesth 2016; 117(Suppl 1): i49-59.

188. Schauer SG, Naylor JF, Chow AL, et al. Survival of casualties undergoing prehospital supraglottic airway placement versus cricothyrotomy. J Spec Oper Med 2019; 19: 91-4.

189. Fadaizadeh L, Hosseini MS, Dabir S. Role of laryngeal mask airway in interventional bronchoscopy procedures for upper tracheal stenosis: case series. Middle East J Anaesthesiol 2013; 22: 223-7.

190. Lee SJ, Lee JN, Kim TS, Park YC. The relationship between the predictors of obstructive sleep apnea and difficult intubation. Korean J Anesthesiol 2011; 60: 173-8.

191. Brodsky JB, Lemmens HJ, Brock-Utne JG, Vierra M, Saidman $L J$. Morbid obesity and tracheal intubation. Anesth Analg 2002; 94: 732-6.

192. Gonzalez H, Minville V, Delanoue K, Mazerolles M, Concina D, Fourcade $O$. The importance of increased neck circumference to intubation difficulties in obese patients. Anesth Analg 2008; 106: $1132-6$

193. Lundstrom LH, Moller AM, Rosenstock C, Astrup G, Wetterslev $J$. High body mass index is a weak predictor for difficult and failed tracheal intubation: a cohort study of 91,332 consecutive patients scheduled for direct laryngoscopy registered in the Danish Anesthesia Database. Anesthesiology 2009; 110: 266-74.

194. Hekiert AM, Mick $R$, Mirza N. Prediction of difficult laryngoscopy: does obesity play a role? Ann Otol Rhinol Laryngol 2007; 116: 799-804.

195. Juvin P, Lavaut E, Dupont $H$, et al. Difficult tracheal intubation is more common in obese than in lean patients. Anesth Analg 2003; 97: 595-600.

196. Mashour GA, Kheterpal S, Vanaharam V, et al. The extended Mallampati score and a diagnosis of diabetes mellitus are predictors of difficult laryngoscopy in the morbidly obese. Anesth Analg 2008; 107: 1919-23.

197. Ezri T, Medalion B, Weisenberg M, Szmuk P, Warters RD, Charuzi $I$. Increased body mass index per se is not a predictor of difficult laryngoscopy. Can J Anesth 2003; 50: 179-83.
198. Neligan PJ, Porter S, Max B, Malhotra G, Greenblatt EP, Ochroch EA. Obstructive sleep apnea is not a risk factor for difficult intubation in morbidly obese patients. Anesth Analg 2009; 109: 1182-6.

199. Combes X, Sauvat $S$, Leroux B, et al. Intubating laryngeal mask airway in morbidly obese and lean patients: a comparative study. Anesthesiology 2005; 102: 1106-9.

200. Kluger MT, Culwick MD, Moore MR, Merry AF. Aspiration during anaesthesia in the first 4000 incidents reported to webAIRS. Anaesth Intensive Care 2019; 47: 442-51.

201. Martin LD, Mhyre JM, Shanks AM, Tremper KK, Kheterpal S. 3,423 emergency tracheal intubations at a university hospital: airway outcomes and complications. Anesthesiology 2011; 114: 42-8.

202. Mort TC. Emergency tracheal intubation: complications associated with repeated laryngoscopic attempts. Anesth Analg 2004; 99: 607-13.

203. Sakles JC, Chiu S, Mosier J, Walker C, Stolz U. The importance of first pass success when performing orotracheal intubation in the emergency department. Acad Emerg Med 2013; 20: 71-8.

204. Cook TM. The cricoid debate - balancing risks and benefits. Anaesthesia 2016; 71: 721-2.

205. Rice MJ, Mancuso AA, Gibbs C, Morey TE, Gravenstein N, Deitte LA. Cricoid pressure results in compression of the postcricoid hypopharynx: the esophageal position is irrelevant. Anesth Analg 2009; 109: 1546-52.

206. Salem MR, Khorasani A, Zeidan A, Crystal GJ. Cricoid pressure controversies: narrative review. Anesthesiology 2017; 126: 738-52.

207. White L, Thang C, Hodsdon A, Melhuish T, Vlok R. Cricoid pressure during intubation: a systematic review and metaanalysis of randomised controlled trials. Heart Lung 2020; 49: 175-80.

208. Birenbaum A, Hajage D, Roche $S$, et al. Effect of cricoid pressure compared with a sham procedure in the rapid sequence induction of anesthesia: the IRIS randomized clinical trial. JAMA Surg 2019; 154: 9-17.

209. Sellick BA. Cricoid pressure to control regurgitation of stomach contents during induction of anaesthesia. Lancet 1961; 2: 404-6.

210. Salem MR, Khorasani A, Saatee S, Crystal GJ, El-Orbany M. Gastric tubes and airway management in patients at risk of aspiration: history, current concepts, and proposal of an algorithm. Anesth Analg 2014; 118: 569-79.

211. Cook T, Frerk C. Aspiration of gastric contents and of blood. In: Cook T, Woodall N, Frerk C, editors. 4th National Audit Project (NAP4). London: The Royal College of Anaesthetists; 2011. p. $155-64$.

212. Windfuhr JP, Schloendorff $G$, Baburi D, Kremer B. Serious post-tonsillectomy hemorrhage with and without lethal outcome in children and adolescents. Int J Pediatr Otorhinolaryngol 2008; 72: $1029-40$.

213. Kristensen MS, McGuire B. Managing and securing the bleeding upper airway: a narrative review. Can J Anesth 2020; 67: 128-40.

214. Sakles JC, Corn GJ, Hollinger P, Arcaris B, Patanwala AE, Mosier JM. The impact of a soiled airway on intubation success in the emergency department when using the GlideScope or the direct laryngoscope. Acad Emerg Med 2017; 24: 628-36.

215. Kristensen $M S, M c$ Guire B. The bloody and bleeding airway. In: Cook T, Kristensen MS, editors. Core Topics in Airway Management. Cambridge: Cambridge University Press; 2020. p. 282-9.

216. Tillquist MN, Gabriel RA, Dutton RP, Urman RD. Incidence and risk factors for early postoperative reintubations. J Clin Anesth 2016; 31: 80-9. 
217. Kellner DB, Urman RD, Greenberg P, Brovman EY. Analysis of adverse outcomes in the post-anesthesia care unit based on anesthesia liability data. J Clin Anesth 2018; 50: 48-56.

218. Difficult Airway Society Extubation Guidelines Group; Popat M, Mitchell $V$, et al. Difficult Airway Society Guidelines for the management of tracheal extubation. Anaesthesia 2012; 67: 318-40.

219. Cavallone LF, Vannucci A. Review article: Extubation of the difficult airway and extubation failure. Anesth Analg 2013; 116: 368-83.

220. Sturgess DJ, Greenland KB, Senthuran S, Ajvadi FA, van Zundert A, Irwin $M G$. Tracheal extubation of the adult intensive care patient with a predicted difficult airway - a narrative review. Anaesthesia 2017; 72: 248-61.

221. Girard TD, Alhazzani W, Kress JP, et al. An official American Thoracic Society/American College of Chest Physicians clinical practice guideline: Liberation from mechanical ventilation in critically ill adults. Rehabilitation protocols, ventilator liberation protocols, and cuff leak tests. Am J Respir Crit Care Med 2017; 195: 120-33.

222. Lee YH, Hsieh PF, Huang HH, Chan KC. Upper airway obstruction after cervical spine fusion surgery: role of cervical fixation angle. Acta Anaesthesiol Taiwan 2008; 46: 134-7.

223. Yoshida M, Neo M, Fujibayashi S, Nakamura T. Upper-airway obstruction after short posterior occipitocervical fusion in a flexed position. Spine (Phila Pa 1976) 2007; 32: E267-70.

224. Tagawa T, Akeda K, Asanuma $Y$, et al. Upper airway obstruction associated with flexed cervical position after posterior occipitocervical fusion. J Anesth 2011; 25: 120-2.

225. Li H, Huang $Y$, Shen $B, B a Z, W u D$. Multivariate analysis of airway obstruction and reintubation after anterior cervical surgery: a retrospective cohort study of 774 patients. Int J Surg 2017; 41: 28-33.

226. Zhou T, Zhang HP, Chen WW, et al. Cuff-leak test for predicting postextubation airway complications: a systematic review. J Evid Based Med 2011; 4: 242-54

227. Ochoa ME, Marin MC, Frutos-Vivar F, et al. Cuff-leak test for the diagnosis of upper airway obstruction in adults: a systematic review and meta-analysis. Intensive Care Med 2009; 35: 1171-9.

228. Kuriyama A, Jackson JL, Kamei J. Performance of the cuff leak test in adults in predicting post-extubation airway complications: a systematic review and meta-analysis. Crit Care 2020; DOI: https://doi.org/10.1186/s13054-020-03358-8.

229. Newmark JL, Ahn YK, Adams MC, Bittner EA, Wilcox SR. Use of video laryngoscopy and camera phones to communicate progression of laryngeal edema in assessing for extubation: a case series. J Intensive Care Med 2013; 28: 67-71.

230. Brull SJ, Kopman AF. Current status of neuromuscular reversal and monitoring: challenges and opportunities. Anesthesiology 2017; 126: 173-90.

231. Hernandez $G$, Vaquero $C$, Colinas $L$, et al. Effect of postextubation high-flow nasal cannula vs noninvasive ventilation on reintubation and postextubation respiratory failure in high-risk patients: a randomized clinical trial. JAMA 2016; 316: 1565-74.

232. Granton D, Chaudhuri D, Wang D, et al. High-flow nasal cannula compared with conventional oxygen therapy or noninvasive ventilation immediately postextubation: a systematic review and meta-analysis. Crit Care Med 2020; 48: e1129-36.

233. Ouellette DR, Patel S, Girard TD, et al. Liberation from mechanical ventilation in critically ill adults: an official American College of Chest Physicians/American Thoracic Society clinical practice guideline: Inspiratory pressure augmentation during spontaneous breathing trials, protocols minimizing sedation, and noninvasive ventilation immediately after extubation. Chest 2017; 151: 166-80.

234. Hernandez $G$, Vaquero $C$, Gonzalez $P$, et al. Effect of postextubation high-flow nasal cannula vs conventional oxygen therapy on reintubation in low-risk patients: a randomized clinical trial. JAMA 2016; 315: 1354-61.

235. Kuriyama A, Umakoshi N, Sun R. Prophylactic corticosteroids for prevention of postextubation stridor and reintubation in adults: a systematic review and meta-analysis. Chest 2017; 151: 1002-10.

236. Mort TC. Continuous airway access for the difficult extubation: the efficacy of the airway exchange catheter. Anesth Analg 2007; 105: 1357-62.

237. Duggan LV, Law JA, Murphy MF. Brief review: Supplementing oxygen through an airway exchange catheter: efficacy, complications, and recommendations. Can J Anesth 2011; 58: 560-8.

238. Cooper RM. The use of an endotracheal ventilation catheter in the management of difficult extubations. Can J Anaesth 1996; 43: 90-3.

239. Cooper RM, Cohen DR. The use of an endotracheal ventilation catheter for jet ventilation during a difficult intubation. Can J Anaesth 1994; 41: 1196-9.

240. Scottish Courts and Tribunals. Inquiry under the fatal accidents and inquiries (Scotland) act 1976 into the sudden death of Gordon Ewing. Available from URL: https://www.scotcourts. gov.uk/search-judgments/judgment?id=328e86a6-8980-69d2b500-ff0000d74aa7 (accessed March 2021).

241. Mort TC, Braffett BH. Conventional versus video laryngoscopy for tracheal tube exchange: glottic visualization, success rates, complications, and rescue alternatives in the high-risk difficult airway patient. Anesth Analg 2015; 121: 440-8.

242. Higgs A, Swampillai $C$, Dravid $R$, et al. Re-intubation over airway exchange catheters - mind the gap. Anaesthesia 2010; 65: 859-60.

243. Fei M, Wanderer JP, Jiang Y, St Jacques PJ. Association between the availability of videolaryngoscopes and the incidence of emergency surgical airway in the perioperative setting of a large academic medical centre: a retrospective observational study. Br J Anaesth 2016; 117: 824-6.

244. McNarry AF, Cook TM, Baker PA, O'Sullivan EP. The Airway Lead: opportunities to improve institutional and personal preparedness for airway management. $\mathrm{Br} \mathrm{J}$ Anaesth 2020; 125: e22-4.

Publisher's Note Springer Nature remains neutral with regard to jurisdictional claims in published maps and institutional affiliations. 